University of South Florida

DIGITAL COMMONS

Digital Commons @ University of

@ UNIVERSITY OF SOUTH FLORIDA

South Florida

\title{
Land Adjacency Effects on MODIS Aqua Top-of-atmosphere Radiance in the Shortwave Infrared: Statistical Assessment and Correction
}

\author{
Lian Feng \\ University of South Florida \\ Chuanmin $\mathrm{Hu}$ \\ University of South Florida, huc@usf.edu
}

Follow this and additional works at: https://digitalcommons.usf.edu/msc_facpub

Part of the Life Sciences Commons

\section{Scholar Commons Citation}

Feng, Lian and Hu, Chuanmin, "Land Adjacency Effects on MODIS Aqua Top-of-atmosphere Radiance in the Shortwave Infrared: Statistical Assessment and Correction" (2017). Marine Science Faculty Publications. 1974.

https://digitalcommons.usf.edu/msc_facpub/1974

This Article is brought to you for free and open access by the College of Marine Science at Digital Commons @ University of South Florida. It has been accepted for inclusion in Marine Science Faculty Publications by an authorized administrator of Digital Commons @ University of South Florida. For more information, please contact digitalcommons@usf.edu. 


\section{Journal of Geophysical Research: Oceans}

\section{RESEARCH ARTICLE \\ 10.1002/2017JC012874 \\ Key Points: \\ Land adjacency effects on MODIS Aqua top-of-atmosphere radiance in the shortwave infrared: Statistical assessment and correction}

- A statistical method was developed to quantify the land adjacency effects in the short-wave infrared signals of MODIS Aqua

- The LAEs are strong functions of $\tau_{869}$ and adjacent land albedo but weak functions of ocean signal and observing geometry

- An LUT to formulate a correction scheme was established, which can be used for LAEs correction for coastal and inland waters

Correspondence to:

C. $\mathrm{Hu}$,

huc@usf.edu

Citation:

Feng, L., and C. Hu (2017), Land adjacency effects on MODIS Aqua top-of-atmosphere radiance in the shortwave infrared: Statistical assessment and correction, J. Geophys. Res. Oceans, 122, 4802-4818, doi:10.1002/2017JC012874.

Received 8 MAR 2017

Accepted 17 MAY 2017

Accepted article online 22 MAY 2017

Published online 13 JUN 2017

(c) 2017. American Geophysical Union. All Rights Reserved.

\author{
Lian Feng1 (D) and Chuanmin Hu' ${ }^{1}$ (D) \\ ${ }^{1}$ College of Marine Science, University of South Florida, St. Petersburg, Florida, USA
}

\begin{abstract}
Satellite measurements of coastal or inland waters near land/water interfaces suffer from land adjacency effects (LAEs), particularly in the short-wave infrared (SWIR) wavelengths. Here a statistical method was developed to quantify the LAEs as the ratio of top-of-atmosphere (TOA) total radiance $\left(L_{t}, W m^{-2} \mu \mathrm{m}^{-1} \mathrm{sr}^{-1}\right.$ ) between near-shore pixels and LAE-free offshore pixels ( $>12$ pixels away from land). The calculations were conducted using MODIS Aqua images between 2003 and 2012 over the Madagascar Island, with results showing the dependency of LAEs on different environmental and observational factors. The LAEs decrease dramatically with increasing distance from shoreline, and increase with decreasing aerosol optical thickness at $869 \mathrm{~nm}\left(\tau_{869}\right)$. The nearby land surface albedo also plays a role in modulating the LAEs, but the impact is only prominent under low-aerosol conditions. Based on these observations, a look-up-table (LUT) to formulate a correction scheme was established. Tests of the correction scheme using satellite observations over the Hawaii Islands and using in situ measurements in the Chesapeake Bay show significant improvements in $L_{t}$ (LAEs much closer to 1 than uncorrected data) and retrieved surface chlorophyll-a concentration $\left(\mathrm{Chl}-\mathrm{a}, \mathrm{mg} \mathrm{m}^{-3}\right)$, respectively. Furthermore, the number of Chl-a retrievals within the range of $0-64 \mathrm{mg} \mathrm{m}^{-3}$ also increases by $>60 \%$. While the ultimate solution of correcting the LAEs for coastal/inland water applications still requires further work, these preliminary results suggest that the method proposed here deserves further tests for other estuaries and lakes.
\end{abstract}

\section{Introduction}

Over the past several decades, satellite ocean color remote sensing has proven to be an effective means to monitor water quality in coastal and inland waters. With moderate spatial resolution, short revising period (1-2 days), high-calibration accuracy, and long-historical measurements (2000-now for Terra and 2002-now for Aqua, respectively), the Moderate Resolution Imaging Spectroradiometer (MODIS) instruments have been used widely to estimate concentrations of several important water quality parameters, including total suspended sediments (TSS, $\mathrm{mg} \mathrm{L}^{-1}$ ), chlorophyll a $\left(\mathrm{Chl}-\mathrm{a}, \mathrm{mg} \mathrm{m}^{-3}\right.$ ), and colored dissolved organic matter $\left(\mathrm{CDOM}, \mathrm{m}^{-1}\right.$ ) [Darecki and Stramski, 2004; Feng et al., 2014; Hu et al., 2004; Miller and McKee, 2004; Werdell et al., 2009 and many others]. However, because these parameters were all derived using remote sensing algorithms rather than determined from field or laboratory measurements, a critical issue to address is to understand the accuracy or uncertainty in the satellite-derived data products.

One such uncertainty source is atmospheric correction (AC), which is to remove the atmospheric effects from the satellite-measured top-of-atmosphere (TOA) radiance $\left(L_{t}, W m^{-2} \mu m^{-1} s r^{-1}\right)$ to obtain waterleaving radiance $\left(L_{w}, W m^{-2} \mu m^{-1} s r^{-1}\right)$ or surface remote sensing reflectance $\left(R_{r s}, s r^{-1}\right)$. This is because $L_{w}$ of certain spectral regions only accounts for $<10 \%$ of $L_{t}$ for most ocean waters [Gordon, 1997], making it difficult to remove the atmospheric effects accurately. For clear waters (e.g., Chl-a $<0.25 \mathrm{mg} \mathrm{m}^{-3}$ ), the standard AC algorithm used by the U.S. NASA assumes $L_{w}=0$ in the infrared (NIR) spectral region, where $L_{t}$ in the NIR is used to derive atmospheric contributions in the visible wavelengths based on radiative transfer simulations and pre-established look-up-tables (LUTs) [Gordon and Wang, 1994]. Such an approach led to retrievals of high-quality $\mathrm{R}_{\mathrm{rs}}$ over clear waters, with Root Mean Square (RMS) uncertainties in the blue wavelengths of generally in the range of $0.0005-0.001 \mathrm{sr}^{-1}$ [Hu et al., 2013; Moore et al., 2015]. For turbid coastal and inland waters where $L_{w}(N I R)$ is no longer 0 , the spectral bands used in the AC can be shifted to longer wavelengths to the shortwave infrared (SWIR) [Wang and Shi, 2007], as the high water absorption in the 


\section{QAGU Journal of Geophysical Research: Oceans}
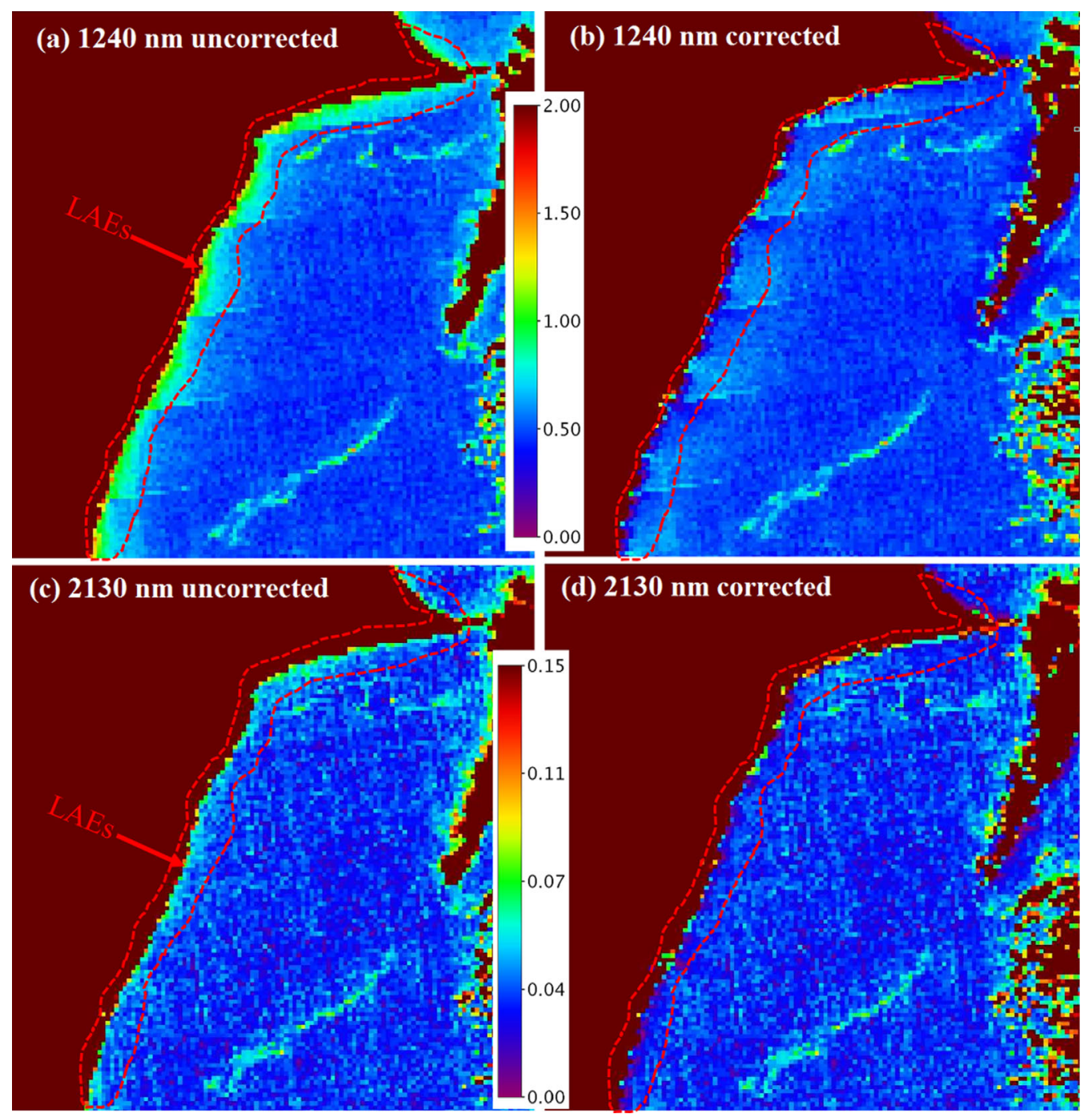

Figure 1. MODISA $L_{t}$ (in $\mathrm{W} \mathrm{m}^{-2} \mu \mathrm{m}^{-1} \mathrm{sr}^{-1}$ ) in the SWIR bands at (a) $1240 \mathrm{~nm}$ and (c) $2130 \mathrm{~nm}$ on 9 June 2003, where the LAEs are prominent near the coastline with elevated signals (circled with red dashed lines). The same $L_{t}$ after correction of the LAEs (using the LUT in Table 1) are shown in Figures $1 \mathrm{~b}$ and $1 \mathrm{~d}$. The location of the image is outlined in Figure 2 as a dashed red box.

SWIR wavelengths makes $L_{w}(S W I R)=0$. As a result, the SWIR based AC has been validated in several studies using global and regional data sets, highlighting its effectiveness in both coastal oceans and inland lakes [Shi and Wang, 2012; Wang et al., 2009]. Simulation studies also showed that for typical maritime aerosols with an aerosol optical thickness at $869 \mathrm{~nm}\left(\tau_{869}\right)$ of 0.1 , inherent uncertainties in the AC will result in $R_{r s}$ uncertainties of $\sim 0.0002 \mathrm{sr}^{-1}$ in the blue wavelengths [Wang et al., 2012], representing a theoretical limit of this AC approach. When sensor noise is induced in the SWIR bands due to the low signal-to-noise ratio (SNR), uncertainties in the AC would increase [Wang et al., 2012]. Such uncertainties, combined with noiseinduced uncertainties in the visible bands and other sensor/algorithm artifacts, would ultimately impact data product quality [Qi et al., 2017].

For waters adjacent to land, another uncertainty source is the land adjacency effect. Similar to adjacency effects (AEs) caused by clouds [Feng and $\mathrm{Hu}, 2016$ ], the radiance from the neighboring brighter land pixels may be scattered into the field of view of the dark water pixels, causing "land adjacency effects" (LAEs) [Barnes et al., 1994]. Such effects tend to increase significantly with increasing wavelength due to the increased reflectance contrast between land and water, leading to highly elevated radiance in the SWIR bands [Feng and $\mathrm{Hu}, 2016$ ]. As such, large uncertainties in the satellite-retrieved $\mathrm{R}_{\mathrm{rs}}$ are expected for land adjacent waters if SWIR based AC is used. Figures 1a and 1c illustrate a subset MODIS image covering clear 
coastal waters off the Madagascar Island (see description below), where $L_{t}$ in both SWIR bands (1240 and $2130 \mathrm{~nm}$ ) shows large gradients from inshore to offshore waters. Such gradients are apparently due to the LAEs, for otherwise $L_{t}(S W I R)$ should remain stable due to 0 contribution from water and homogeneous aerosol contribution across the nearshore-offshore waters. Thus, in order to obtain accurate ocean color products over land adjacent waters, LAEs in the SWIR bands need to be removed if SWIR AC is to be used.

Studies of AEs from either clouds or land have started since the 1970s. One typical method is to express the AEs from bright targets through a point spread function (PSF), where contributions from nearby clouds or land to the water pixels can be modeled using radiative transfer (RT) theory based on Monte Carlo simulations [Bulgarelli et al., 2014; Kiselev et al., 2015; Meister and McClain, 2010; Reinersman and Carder, 1995; Santer and Schmechtig, 2000]. In addition, potential AE-related factors such as distance from bright targets, surface cover type, and aerosol type and thickness can all be considered in the model simulations. The potential problem of this method is that the simulated effects may not be representative for real satellite measurements, and thorough simulations for various combinations of the complex environmental and observational conditions require considerable computing resources [Reinersman and Carder, 1995; Santer and Schmechtig, 2000]. On the other hand, the AEs can also be quantitatively estimated using remote sensing images. For example, the cloud AEs on TOA radiance and ocean color products of MODIS and SeaWiFS have been quantified by Feng and $\mathrm{Hu}$ [2016], based on statistical calculations of AEs near cloud-water interfaces.

Even if the AEs can be accurately characterized using either simulations or remote sensing observations, how to correct such effects is still technically challenging. The "solution" of the current NASA standard processing of MODIS images in SeaDAS software is not to correct cloud-adjacent or land-adjacent pixels but to flag these pixels as being of potentially low quality. Specifically, data within a window of $7 \times 5$ pixels centered at a cloud-water or land-water interface pixel will be flagged as stray-light contaminated, and therefore discarded when composing global level-3 data. The selection of the window size is based on simulated PSF effects [Meister and McClain, 2010]. While exclusion of data in the vicinity of clouds will result in a loss of $>50 \%$ cloud-free data [Feng and Hu, 2016], applying the stray-light masks near land-water interface will not only reduce data coverage, but also lead to no data coverage for some small coastal or inland water bodies. Similar flagging and masking schemes are also applied for the Visible-Infrared Imaging Radiometer Suite (VIIRS) onboard the Suomi National Polar-orbiting Partnership (SNPP) satellite [Jiang and Wang, 2013]. However, no systematic study has been found to characterize the LAEs for these instruments, let alone how to minimize or remove them to obtain ocean color products of higher accuracy and coverage.

It is thus desirable to accurately estimate and then effectively remove the LAEs for coastal and inland water applications. The objectives of this study are therefore to:

1. Develop a statistical method to characterize the LAEs of MODIS SWIR bands at 1240 and $2130 \mathrm{~nm}$ (its $1640 \mathrm{~nm}$ band is not functional), and understand the dependency of LAEs on different environmental and observational factors.

2. Derive an LUT that can be used to correct the LAEs and evaluate the performance of the corrections in both data quality and data quantity.

\section{Study Area and Data Sets}

The eastern coastal ocean of the Madagascar Island was selected to estimate the LAEs in this study (see location in Figure 2) for the following reasons: (1) the coastal waters of the eastern Madagascar Island are very clear, where the mean Chl-a concentrations of the entire MODIS Aqua mission (subset from NASA generated Chl-a level-3 composite, with the time period of June 2002 to August 2016) is generally $<0.5 \mathrm{mg}$ $\mathrm{m}^{-3}$. Thus, $\mathrm{L}_{w}(\mathrm{SWIR})$ should be negligible, and $\mathrm{L}_{t}(\mathrm{SWIR})$ of near-shore waters only comes from atmospheric path radiance and the associated LAEs. (2) The Madagascar Island has a very long and straight eastern coastline, where land "contamination" to the ocean signal is only from one direction, making it relatively easier to study LAEs than from more morphologically complex coastlines. Further, the long coastline $(>1000 \mathrm{~km}$ ) provides sufficient land-water interface to conduct a statistical assessment of the LAEs using satellite observations. (3) As the scan direction of MODIS Aqua is from the east to the west (see Figure 2) [Feng and Hu, 2016], the ocean pixels to the east of the island will not suffer from memory effects (MEs) of 


\section{QAGU Journal of Geophysical Research: Oceans}
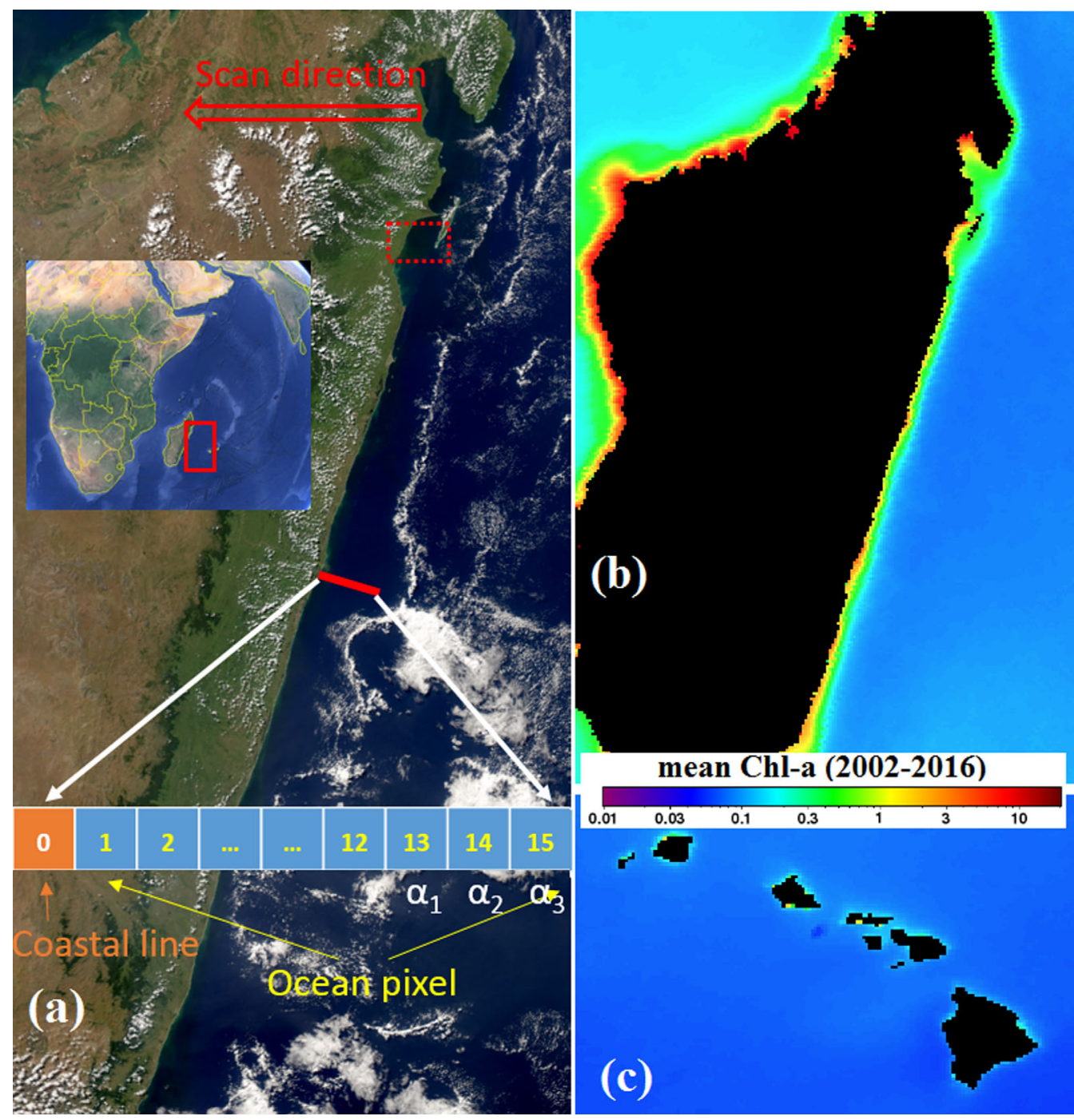

Figure 2. MODIS Red-Green-Blue (RGB) true color image showing the location of Madagascar Island, where MODIS Aqua data between 2003 and 2012 were used to calculate the LAEs for two SWIR bands at 1240 and $2130 \mathrm{~nm}$. The concept of how to estimate the LAEs for a certain transect that is perpendicular to the coastal line is also demonstrated. The scan direction of MODIS Aqua is also annotated. The climatological MODISA Chl-a concentration (2002-2016) of the coastal Madagascar and Hawaii Islands is demonstrated in Figures 2b and 2c, respectively.

the satellite instruments [Feng and Hu, 2016]. Otherwise, if the location is selected to the west of the land, further work is required to separate MEs from LAEs.

A 11-year time series of Level-1A MODIS Aqua Local-Area-Coverage (LAC) data between 2003 and 2012 covering the east coast of the Madagascar Island was obtained from the NASA Goddard Space Flight Center (>5000 granules), where the satellite measurements included all possible environmental data (e.g., sea surface features, aerosol type, and optical thickness) and satellite/solar geometries for this region. These MODIS data were processed using the software package SeaDAS (version 7.2) to derive the $L_{t}, \tau_{869}$, as well as the solar and satellite viewing zenith and azimuth angles.

To evaluate the performance of the LAE corrections for coastal waters other than the Madagascar Island, Level-1A MODIS Aqua LAC data covering the Hawaii Islands were also downloaded and processed. The selection criteria of the Hawaii Islands were similar to those of the Madagascar Island, where the coastal waters are very clear and the $L_{w}(S W I R)$ is negligible. Additional evaluation of the LAE corrections was also conducted on Chl-a retrievals in the Chesapeake Bay, where concurrent MODIS Aqua LAC data and NOMAD (NASA bio-Optical Marine Algorithm Data set) [Werdell and Bailey, 2005] archived in situ Chl-a data were also obtained. 
To test if the LAEs can be generalized for different instruments, Landsat OLI, ETM+, and TM data covering the coastal Madagascar Island were also downloaded from the USGS (glovis.usgs.gov/).

\section{Estimation of the LAEs on MODIS SWIR Bands}

\subsection{LAEs Calculation Method}

To estimate the LAEs, the land-water boundaries (or shorelines) need to be identified first. Various methods can be used to determine the shorelines. For example, shorelines can be obtained directly from the Global Self-consistent, Hierarchical, High-resolution Geography Database (GSHHG) [Wessel and Smith, 1996], where the high spatial resolution data can be resampled to $500 \mathrm{~m}$ resolution of the MODIS SWIR bands. In addition, band combinations such as the normalized difference vegetation index (NDVI) and normalized difference water index (NDWI) can also be used to delineate the image-specific land-water interfaces. In this study, we used the standard SeaDAS ocean color processing method to determine shorelines in order to assure consistency in the subsequent LAE estimation and correction. Specifically, bit \#1 in the 32-bit "I2_flags" is used to delineate land, and shoreline pixels were determined using a morphological edge detection algorithm. Then, similar to the method used in Feng and $\mathrm{Hu}$ [2016] for estimating cloud adjacency effects, LAEs on $L_{t}($ SWIR) were also calculated as a function of distance (\# of pixels) between the current pixel and the shoreline (denoted as Dist). The following steps were used to estimate the LAEs:

Step 1. Qualified land-water transects were selected to be perpendicular to the shoreline. For a certain pixel on the shoreline (e.g., pixel 1 in Figure 2a), find its land-water transect that is perpendicular to the shoreline around the pixel. A transect through the shoreline pixel and 15 water pixels was selected (see Figure 2a). For any pixel on this transect, there should be at least 10 adjacent cloud-free pixels (determined with the cloud flag "CLDICE" in the SeaDAS "I2_flags" data product) to eliminate potential cloudadjacency influence.

Step 2. Of the selected 15 water pixels, the three pixels away from shoreline (denoted as " $\alpha_{1}, \alpha_{2}$, and $\alpha_{3}$ " in Figure $2 \mathrm{a}$ ) were assumed to be not affected by LAEs, and were therefore used as the references. The ratios between the other 12 pixels and the mean value of the three reference pixels were estimated as:

$$
\text { Ratio }_{\mathrm{i}}=\mathrm{L}_{\mathrm{t}, \mathrm{i}} / \text { mean }\left(\mathrm{L}_{\mathrm{t}, \alpha 1}+\mathrm{L}_{\mathrm{t}, \alpha 2}+\mathrm{L}_{\mathrm{t}, \alpha 3}\right)
$$

where $L_{t, \alpha 1-3}$ are the TOA radiance of the three reference pixels and $L_{t i}$ are the TOA radiance of the other 12 pixels. The Dist for the reference pixels (e.g., >12 pixels) was determined through trial and error, where the LAEs were determined to be negligible for Dist by $>12$ pixels (see results below). Therefore, the ratio in equation (1) was used to represent the LAEs. A ratio of 1.0 means no LAEs, and a ratio of $>1.0$ means nonzero LAEs. Then, for each transect, $L_{t}$ of the adjacent land (represented by the mean value of a $3 \times 3$ pixel window centered at the shoreline pixel but excluding water pixels), mean $L_{t}$ and mean $\tau_{869}$ of the reference pixels, and the estimated LAEs (i.e., ratios in equation (1)) for the 12 affected coastal water pixels were recorded. In this step, the use of three reference pixels instead of one is to reduce the effects of speckle noise on the LAEs due to the low signal-to-noise ratio of MODIS SWIR bands [Hu et al., 2012] and to reduce other potential artifacts.

Step 3. The above two steps were repeated for all qualified land-water transects for the entire MODIS data sets between 2003 and 2012 that were acquired under various observational conditions, to obtain sufficient calculations that can be further used to produce statistically meaningful LAEs.

\subsection{Sensitivity Analysis of the LAEs}

To derive representative LAEs under different observational and geometrical conditions, the factors impacting the LAEs were determined. We examined the sensitivity of the LAEs to four parameters including: (1) signal level of the adjacent land, which was defined by $L_{t, 1240}$ of the shoreline pixel in each land-water transect $\left(L_{t} \_\right.$land at $\left.1240 \mathrm{~nm}\right) ;(2)$ radiance over LAE-free ocean pixels, represented by the mean $L_{t, 1240}$ of the three reference pixels of each transect $\left(L_{t_{-} \text {ocean }}\right)$; (3) aerosol optical thickness, estimated using the mean $\tau_{869}$ of the three reference pixels of each transect; and (4) accumulated effects of the observation geometry (or aerosol scattering phase function), which depends on the scattering angle $(\phi)$ and can be expressed as [Levy et al., 2007]: 

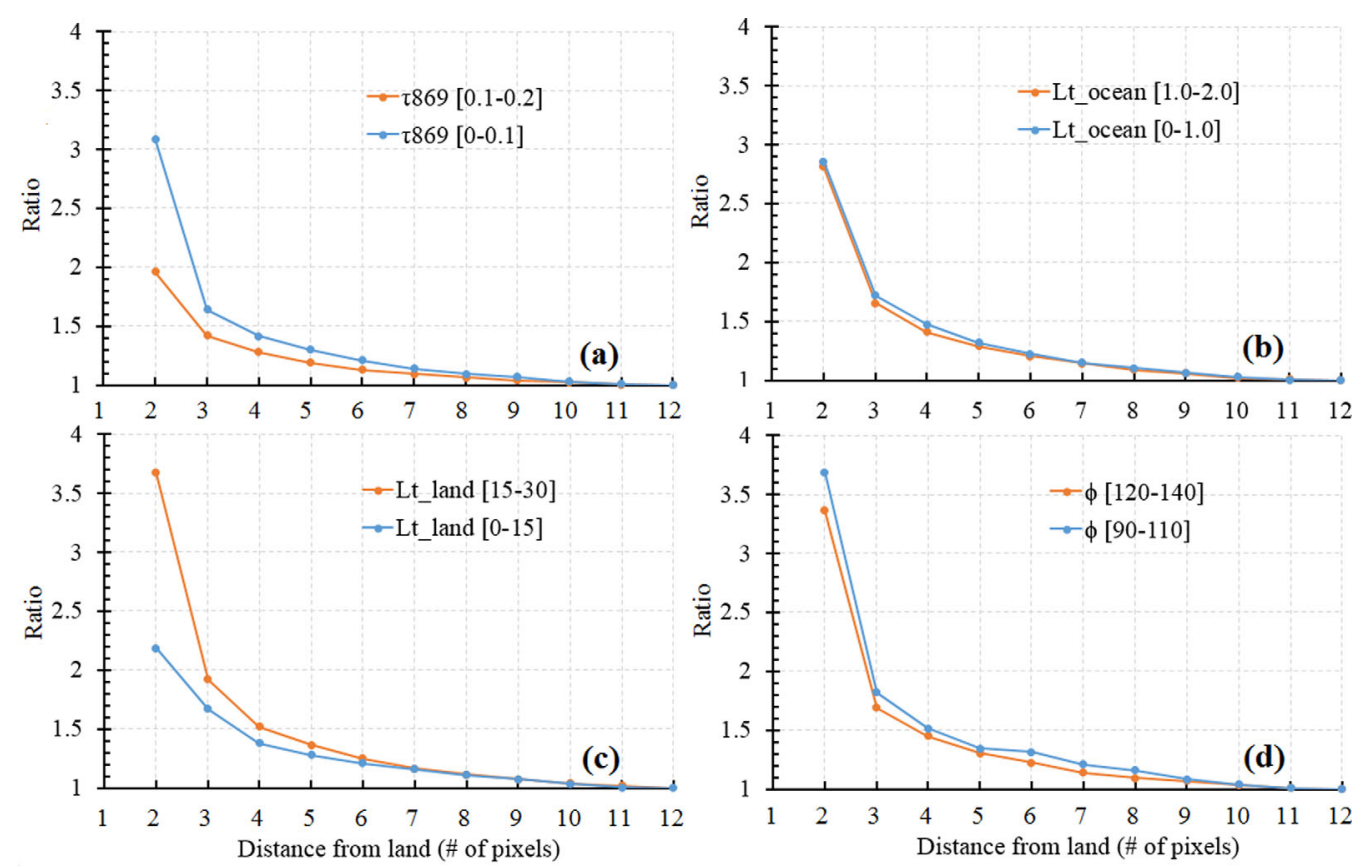

Figure 3. LAEs of MODIS Aqua, expressed as the ratio of $L_{t}$ of the current pixel and a remote pixel ( 12 pixels away from land). $A$ ratio $=1.0$ means no LAEs from the current pixel, and a ratio of $>1.0$ indicates nonzero LAEs. Here the LAEs are expressed in response to different (a) aerosol optical thicknesses $\left(\tau_{869}\right)$, (b) ocean signals ( $L_{t}$ ocean, which is the $L_{t, 1240}$ of nearby $L A E-f r e e$ ocean pixels), (c) adjacent land signals ( $L_{t \_l a n d}$, which is $L_{t, 1240}$ of the closest shoreline pixels), and (d) scattering angles ( $\phi$, which is a function of the observing geometry). For each plot where one variable is changed, other variables remain the same: $0.05-0.07$ for $\tau_{869}, 20-25 \mathrm{~W} \mathrm{~m}^{-2} \mu \mathrm{m}^{-1} \mathrm{sr}^{-1}$ for $\mathrm{L}_{\mathrm{t} \_l a n d}, 0.8-1.2$ $W \mathrm{~m}^{-2} \mu \mathrm{m}^{-1} \mathrm{sr}^{-1}$ for $\mathrm{L}_{\mathrm{t} \_o c e a n}$, and $120^{\circ}-140^{\circ}$ for $\phi$. It appears that LAEs are strong functions of $\tau_{869}$ and adjacent $L_{t} \_$land but weak functions of $L_{t}$ ocean and observing geometry. The distance is expressed as \# of 500-m pixels.

$$
\phi=\cos ^{-1}\left(-\cos \theta_{0} \cos \theta+\sin \theta_{0} \sin \theta \cos \psi\right)
$$

where $\theta_{0}, \theta$, and $\psi$ are the solar zenith angle, satellite view zenith angle, and the relative azimuth angle between the sun and satellite, respectively. For brevity, sensitivity analysis of the MODIS $1240 \mathrm{~nm}$ band is illustrated here, but results for the $2130 \mathrm{~nm}$ band are very similar.

The dependency of LAEs on these factors were studied using the univariate analysis method. Specifically, when analyzing one factor, the other three factors were confined within some narrow ranges, and only the transects with the three factors falling within these ranges were selected. The corresponding mean LAEs for these transects were then estimated and partitioned into two groups according to the range of the factor under examination. For example, when testing the dependence of LAEs on $\tau_{869}$, the land-water transects with Lt_land of $20-25 \mathrm{w} \mathrm{m}^{-2} \mu \mathrm{m}^{-1} \mathrm{sr}^{-1}, \mathrm{~L}_{\mathrm{t}}$ ocean of $0.8-1.2 \mathrm{w} \mathrm{m}^{-2} \mu \mathrm{m}^{-1} \mathrm{sr}^{-1}$, and $\phi$ of $120^{\circ}-140^{\circ}$ were selected, and the mean LAEs of these transects were estimated and separated into two groups for $\tau_{869}=0$ 0.1 and $0.1-0.2$, respectively.

\section{Results}

\subsection{LAEs of MODISA $L_{t, 1240}$ and $L_{t, 2130}$}

Figures $3 a-3 d$ show the dependency of the LAEs on $\tau_{869}$, $L_{t \_o c e a n}$ Lt_land, and $\phi$, respectively. A ratio of $>1.0$ indicates nonzero LAEs. In this analysis, results for pixels just near the shoreline (Dist $=1$ pixel) were excluded, as they may be mixed land-water pixels due to the relative low spatial resolution (500 $\mathrm{m}$ ) and pixel registration errors (usually about 0.5 pixel). Discernable disparities can be found between the LAEs of different levels of $\tau_{869}\left(0-0.1\right.$ and $0.1-0.2$, Figure 3a), where lower $\tau_{869}$ showed higher LAEs for all pixels. This could be explained by the increased surface-to-sensor transmittance and decreased atmospheric contribution to total radiance with decreased aerosol thickness [Minomura et al., 2001], leading to higher LAEs on low-aerosol loads. Additionally, larger Lt_land (15-30 $\mathrm{w} \mathrm{m}^{-2} \mu \mathrm{m}^{-1} \mathrm{sr}^{-1}$ ) showed higher LAEs than low Lt_land (0-15 w m $\mathrm{w}^{-2} \mathrm{~m}^{-1} \mathrm{sr}^{-1}$ ) (Figure 3c), indicating that a brighter adjacent land surface could introduce 
larger LAEs. On the other hand, the ratios were generally the same for different $L_{t}$ ocean and $\phi$, suggesting that LAEs are insensitive to these two factors.

From the above analysis, the LAEs estimated using equation (1) for all qualified land-water transects $(>20,000)$ were binned together according to different ranges of $\tau_{869}(0-0.05,0.05-0.1,0.1-0.15,0.15-0.2$, and $>0.2)$ and $L_{t}$ of adjacent shoreline pixels (i.e., $\left.L_{t \_l a n d}\right)\left(0-8,8-16,16-24,24-32\right.$, and $>32 \mathrm{w} \mathrm{m}^{-2} \mu \mathrm{m}^{-1}$ $\mathrm{sr}^{-1}$ for $1240 \mathrm{~nm}$ band and 0-0.8, 0.8-1.6, 1.6-2.4, 2.4-3.2, and $>3.2 \mathrm{w} \mathrm{m}^{-2} \mu \mathrm{m}^{-1} \mathrm{sr}^{-1}$ for $2130 \mathrm{~nm}$ band). Two criteria were followed to determine the five binning ranges for both $\tau_{869}$ and $L_{t}$ land: (1) For each binning combination of $\tau_{869}$ and $L_{t \_l a n d}$, there were sufficient number of transects ( $>50$ in practice) to derive statistically meaningful results and (2) the intervals of $\tau_{869}$ and $\mathrm{L}_{\mathrm{t} \_ \text {land }}$ were evenly distributed in linear space. Because LAEs were estimated as a function of Dist, the calculations resulted in 25 mean LAEs $\left(5 L_{t}\right.$ land $\times 5$ $\tau_{869}$ bins) for each pixel from 2 to 12 pixels away from shoreline.

Figure 4 shows the mean LAEs of MODIS $L_{t, 1240}$ under different combinations of $L_{t \_l a n d}$ and $\tau_{869}$, where each plot represents a finite Dist (1-12 pixels). The absence of LAE estimates for several combinations is due to the limited number (e.g., <50) of land-water transects that could be used to derive statistically meaningful calculations.

The LAEs decrease significantly away from shoreline, and then approach 1.0 (i.e., negligible LAEs). For example, under low-aerosol conditions $\left(\tau_{869}=0-0.05\right)$, ocean pixels with $2-3$ pixels Dist showed a ratio of $>2.0$, and the ratio decreased to $<1.5$ for pixels with 6 pixels Dist and further decreased to $<1.01$ for pixels with 12 pixels Dist. Here although pixel \#1 (first plot) may be mixed between land and water the results are still plotted as references.

The LAEs also decrease sharply with increasing $\tau_{869}$. For example, for data 2 pixels way from shoreline (Figure $4 b$ ), for $L_{t}$ land between $16-24 \mathrm{w} \mathrm{m}^{-2} \mu \mathrm{m}^{-1} \mathrm{sr}^{-1}$ (i.e., $L_{\mathrm{t} 3}$ in the graph), LAEs decreased from 3.63 at $\tau_{869}$ $<0.05$ to $<2$ at $\tau_{869}>0.1$. Similar changing patterns were also found for other $L_{t}$ land ranges and for pixels with other Dist, highlighting the strong dependency of LAEs on aerosol load.

LAEs also change considerably with $L_{t} \_$land, particularly under low-aerosol conditions $\left(\tau_{869}=0-0.05\right)$. LAEs generally increase with increasing $L_{t \_l a n d}$ for $\tau_{869}$ between 0 and 0.05 for all plots. For example, if the pixel of interest is 2 pixels away from shoreline for $\tau_{869}=0-0.05$, LAEs decreased from $>3.5$ to 1.57 when $L_{t} \_$land decreased from $>16$ to $0-8 \mathrm{w} \mathrm{m}^{-2} \mu \mathrm{m}^{-1} \mathrm{sr}^{-1}$. Similar patterns were found for pixels with different Dist. However, when $L_{t}$ land reached a certain level $\left(>16 \mathrm{w} \mathrm{m}^{-2} \mu \mathrm{m}^{-1} \mathrm{sr}^{-1}\right)$, LAEs tended to be plateaued. Additionally, with increased Dist or increased $\tau_{869}$, sensitivities of LAEs on $L_{t \_l a n d}$ decreased rapidly. Specifically, for $\tau_{869}>0.1$ or for Dist $>8$ pixels, LAEs remained stable regardless of changes in $\mathrm{L}_{\mathrm{t} \_ \text {land }}$.

The three-dimesional plots of LAEs on MODIS $\mathrm{L}_{t, 2130}$ are demonstrated in Figure 5, where their responses to $\tau_{869}$ and $L_{t}$ land $c a n$ be clearly observed within each plot corresponding to a fixed Dist. These patterns are very similar to that of $L_{t, 1240}$, where LAEs decrease with increased $\tau_{869}$ or Dist. Additionally, larger $L_{t} \_$land showed higher LAEs, especially under low-aerosol conditions. Moreover, $L_{t, 2130}$ appears to have higher LAEs than $L_{t, 1240}$ for $\tau_{869}$ between 0 and 0.05 .

\subsection{Correction of LAEs}

Because LAEs decrease dramatically with increasing $\tau_{869}$ regardless of the $L_{t}$ land ranges (Figures 4 and 5 ), a power law regression could well explain the relationships between LAEs and $\tau_{869}$ : LAEs $=\left(\tau_{869}\right)^{\mathrm{a}} \times \mathrm{b}$, where $a$ and $b$ are the regression coefficients, with the coefficients of determination $\left(R^{2}\right)$ generally $>0.95$. Therefore, a look-up-table (LUT) for LAEs was generated to contain the $a$ and $b$ values for each Dist and $L_{t}$ land (Table 1). From this table, once $\tau_{869}$ is known from the LAE-free pixels, LAEs can be estimated for each pixel as a function of Dist and $L_{t}$ land. The LUT was designed to estimate LAEs for Dist $\leq 10$ pixels only, as they tend to be negligible for Dist $>10$ pixels (Figures 4 and 5).

Corrections of LAEs using the LUT above have been tested from MODISA observations near the Hawaii Islands (for clear waters) and over the Chesapeake Bay (for turbid waters), through the following steps:

Step 1. Generate MODISA level-2 data products, including $L_{t, 1240}, L_{t, 2130}, \tau_{869}$, and $I_{2}$ flags, from MODISA Level-1A data. 

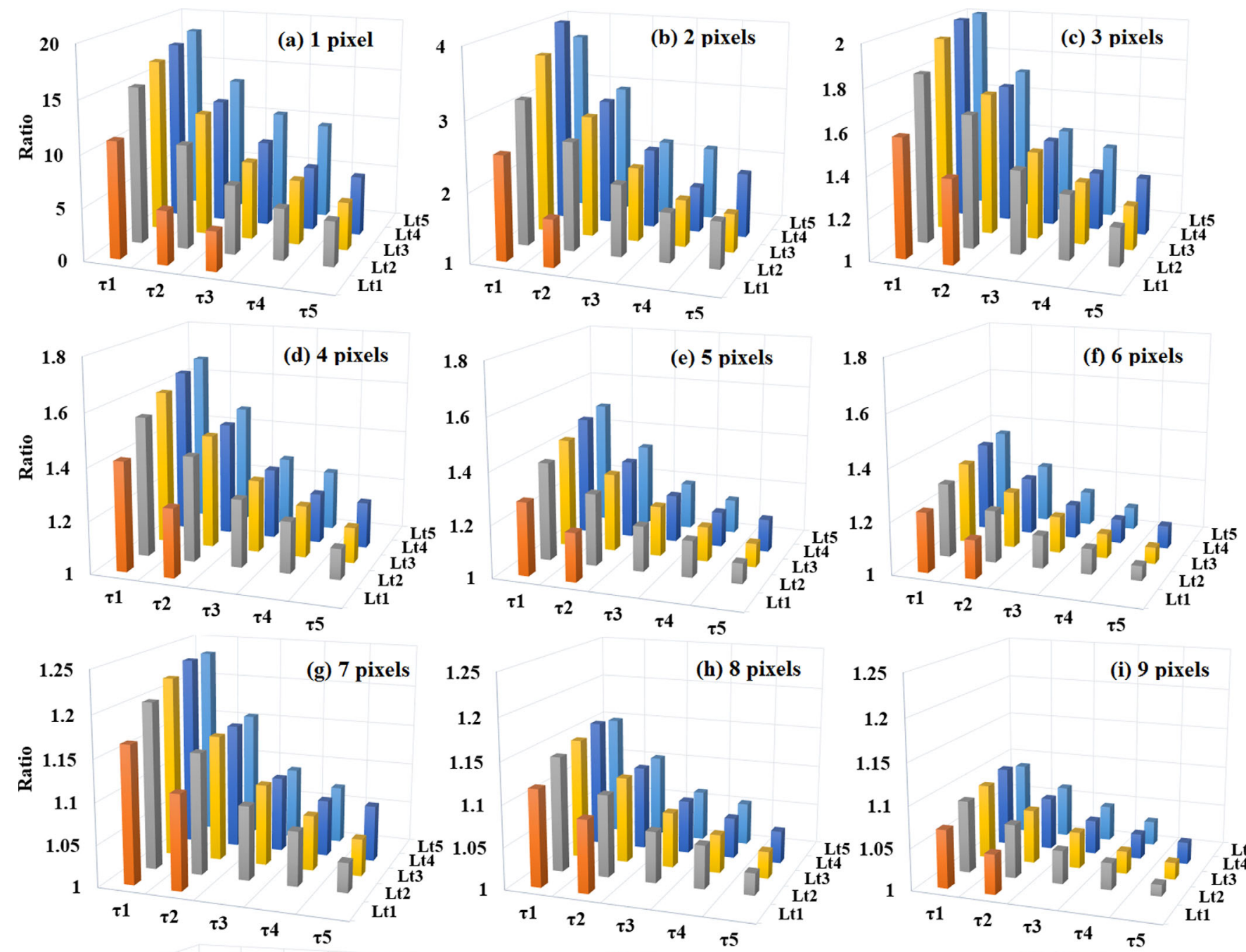

(h) 8 pixels

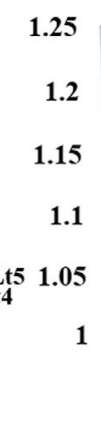

(k) 11 pixels
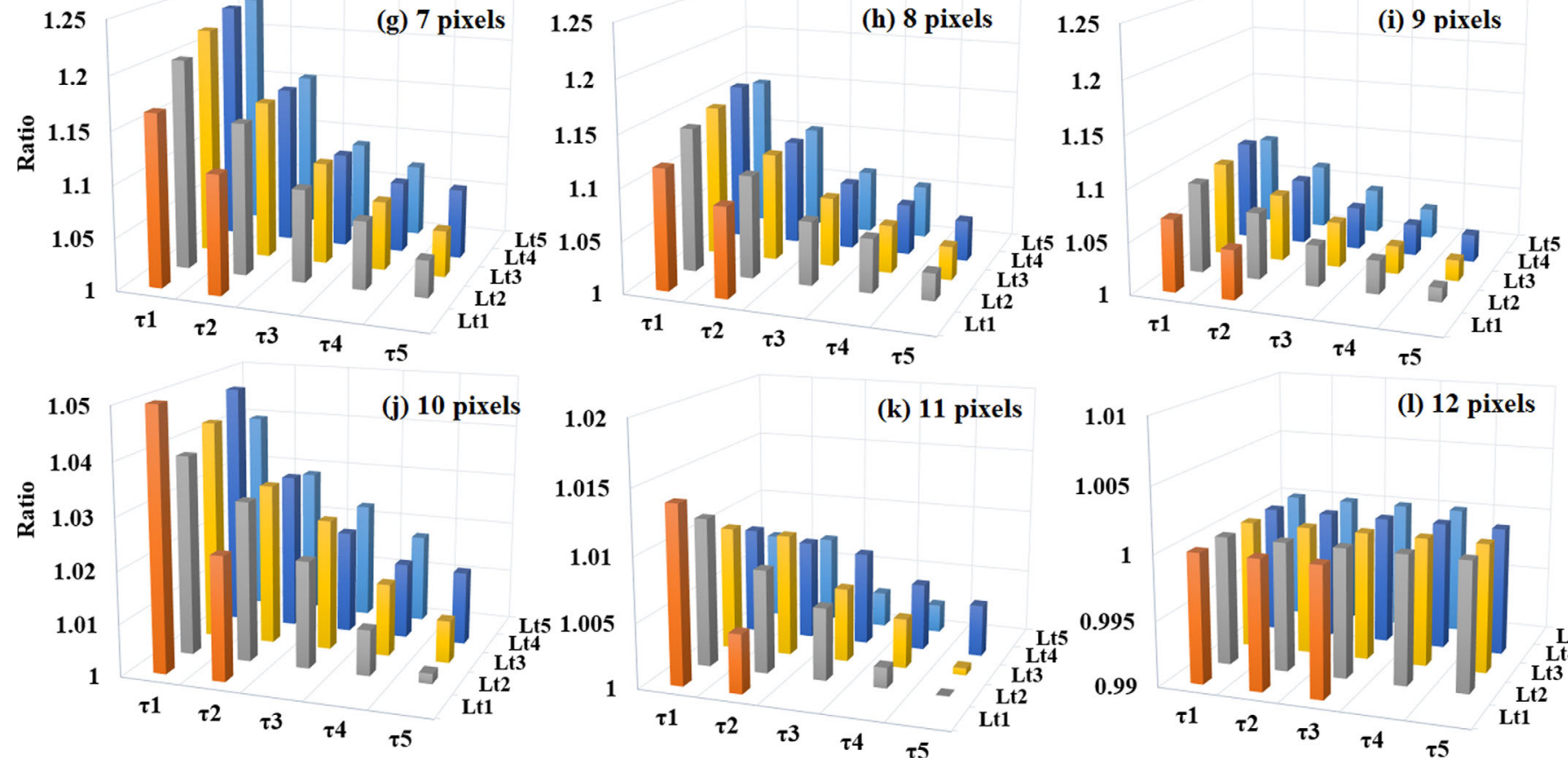

(i) 9 pixels

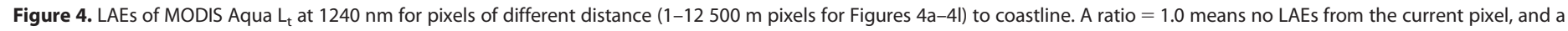

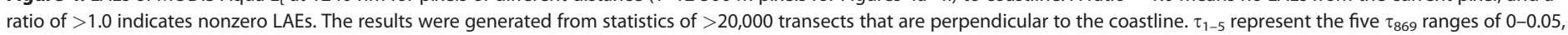
$0.05-0.1,0.1-0.15,0.15-0.2$, and $>0.2$, respectively, and $L_{t 1-5}$ represent the five $L_{t} \_$land $(1240 \mathrm{~nm})$ ranges of $0-8,8-16,16-24,24-32$, and $>32 \mathrm{~W} \mathrm{~m}^{-2} \mu \mathrm{m}^{-1} \mathrm{sr}^{-1}$, respectively.

Step 2. Determine shoreline pixels using 12_flags (LAND), and then determine the land-water transect perpendicular to each shoreline pixel. Along each transect, estimate $L_{t \_l a n d}$ of the shoreline pixel and mean $\tau_{869}$ $\left(\tau^{\prime}{ }_{869}\right)$ of the five valid pixels with Dist $>10$ (i.e., away from shoreline).

Step 3. Estimate LAEs for each pixel along the transect with Dist $\leq 10$ using $L_{t \_l a n d} \tau^{\prime}{ }_{869}$, and the LUT in Table 1. For most cases, $L_{t} \_$land falls between two values in the LUT, where a linear interpolation was used to determine the LAEs. 

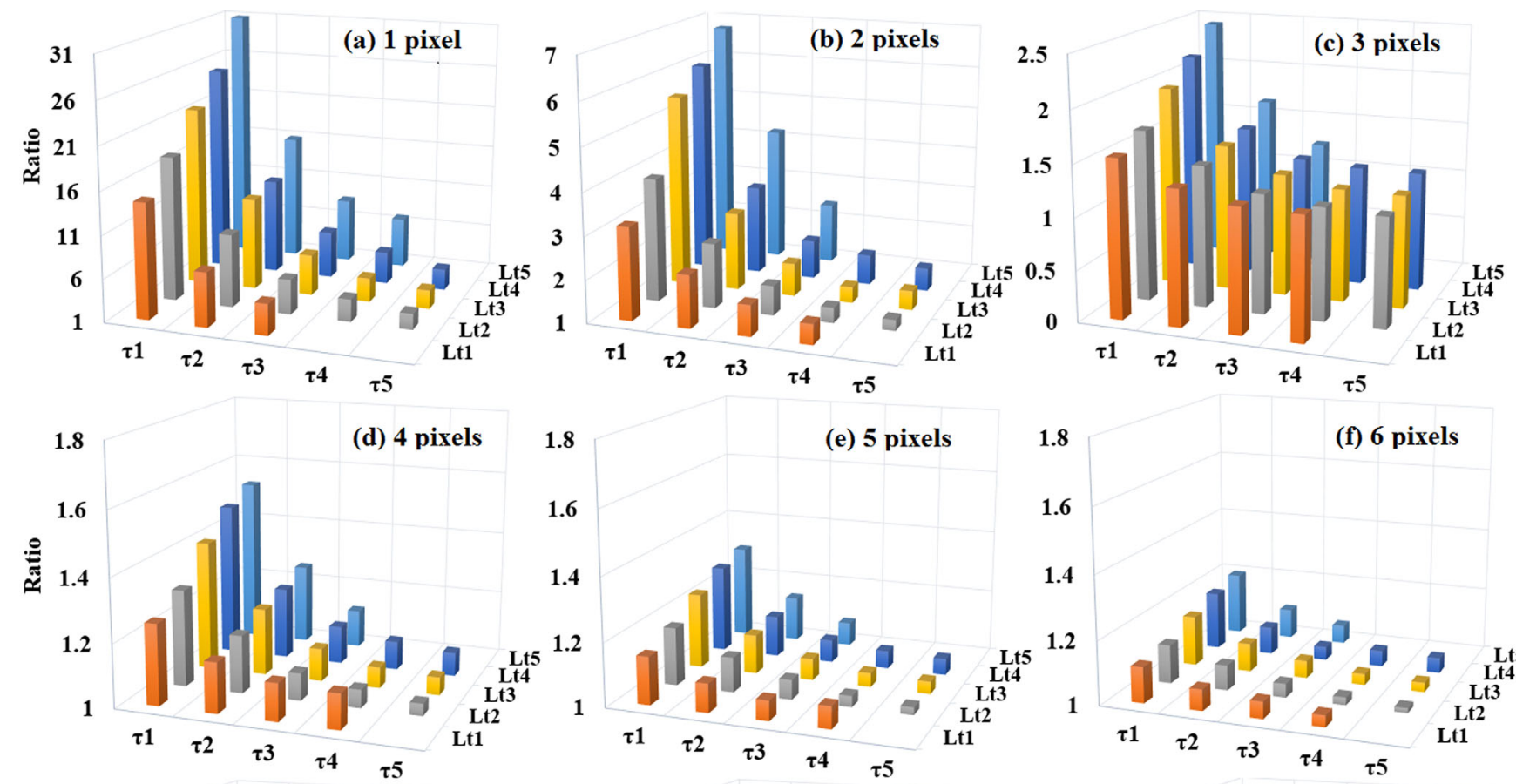

(e) 5 pixels

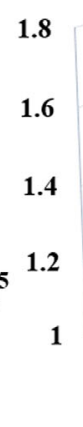

(f) 6 pixels
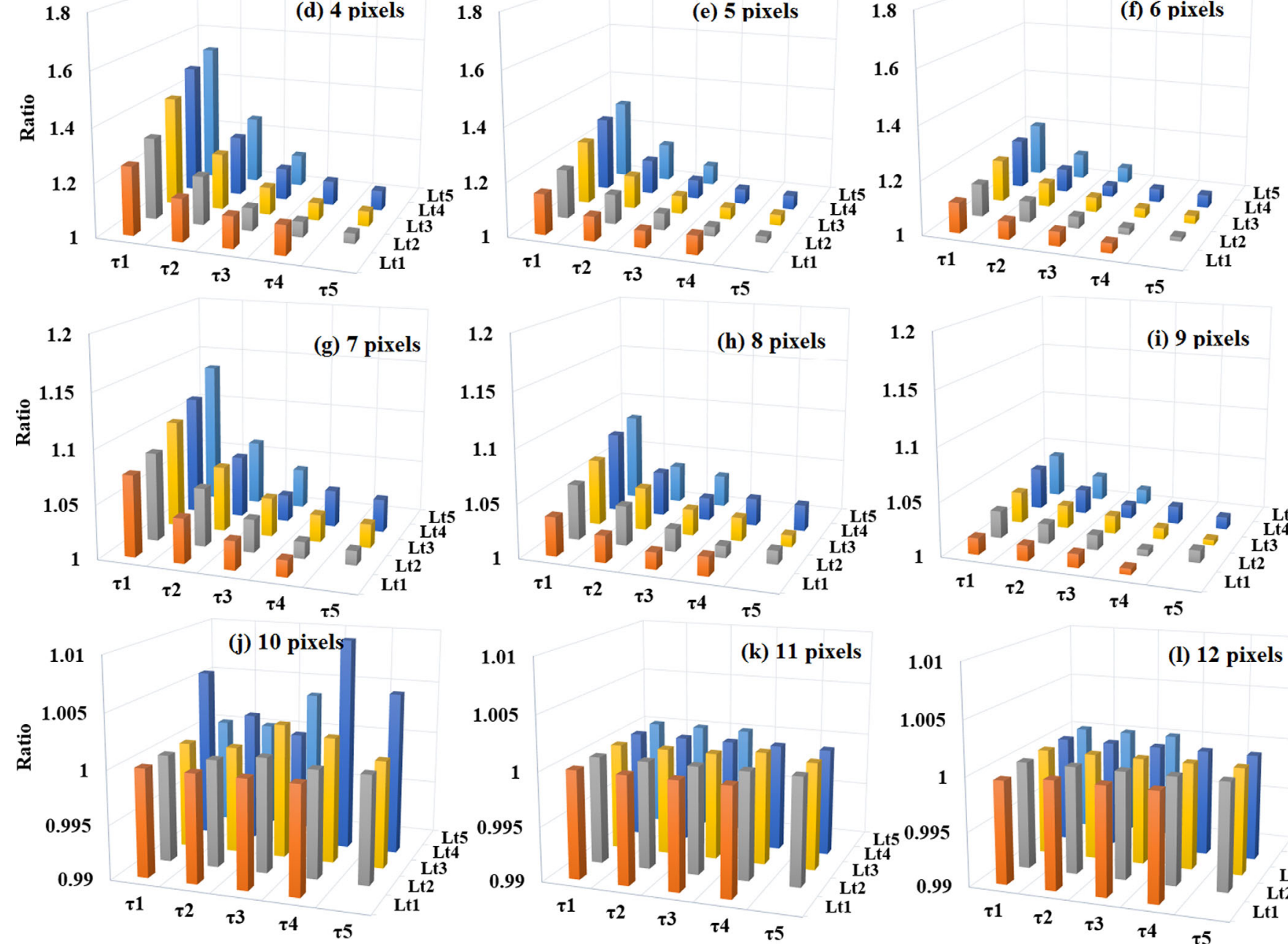

(h) 8 pixels

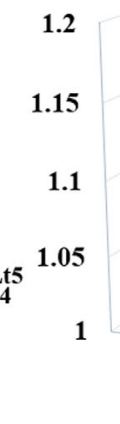

(k) 11 pixels
1.01

1.005

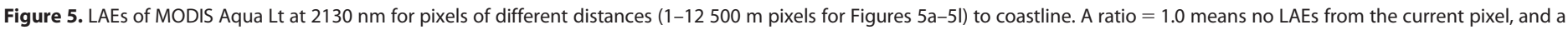
ratio of $>1.0$ indicates nonzero LAEs. The results were generated from the statistics of $>20,000$ transects that are perpendicular to the coastline. $\tau_{1-5}$ represent the five $\tau_{869}$ ranges of

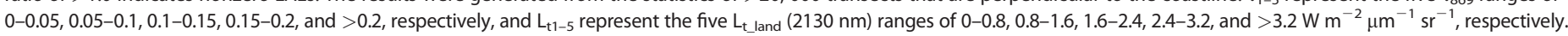

Step 4. The $L A E$-corrected $L_{t}\left(L_{t}{ }^{\prime}\right)$ for the $10 \mathrm{LAE}$-affected pixels can be calculated as $\mathrm{L}_{t}{ }^{\prime}=\mathrm{L}_{t} / \mathrm{LAE}$, which is then used in the SeaDAS module I2gen to generate $\mathrm{R}_{\mathrm{rs}}$ and other data products such as Chl-a.

4.2.1. Performances of the LAEs Correction on $L_{t}$

Figure 1 compared the MODIS Aqua $L_{t}$ image over the Madagascar Island before and after correction of the LAEs, and the data of one typical transect is shown in Figure 6a. Compared with the original uncorrected data, the spatial gradient of $L_{t}$ along the land-water transects, attributed to the LAEs, have been reduced for both bands. 
Table 1. LUT of the LAEs for MODISA 1240 and 2130 nm Bands Estimated Using Coastal Ocean Data Obtained From the Madagascar Island Between 2003 and 2012

\begin{tabular}{|c|c|c|c|c|c|c|}
\hline \multirow[b]{2}{*}{ Dist } & \multicolumn{3}{|c|}{$1240 \mathrm{~nm}$} & \multicolumn{3}{|c|}{$2130 \mathrm{~nm}$} \\
\hline & $\mathrm{L}_{\mathrm{t} \_ \text {land }}$ & a & $b$ & $\mathrm{~L}_{\mathrm{t} \_ \text {land }}$ & a & $b$ \\
\hline 1 & 5.78 & 0.4503 & -0.9773 & 0.63 & 0.6579 & -0.9333 \\
\hline 1 & 13.33 & 1.5180 & -0.7028 & 1.16 & 0.6285 & -1.0199 \\
\hline 1 & 19.61 & 1.7678 & -0.6979 & 1.93 & 0.5980 & -1.1030 \\
\hline 1 & 27.41 & 2.1656 & -0.6402 & 2.74 & 0.6394 & -1.1226 \\
\hline 1 & 37.13 & 3.8214 & -0.4775 & 3.89 & 0.9489 & -1.0696 \\
\hline 2 & 5.78 & 0.6418 & -0.4082 & 0.63 & 0.6480 & -0.4782 \\
\hline 2 & 13.34 & 0.9623 & -0.3613 & 1.16 & 0.4633 & -0.6412 \\
\hline 2 & 19.61 & 0.7648 & -0.4778 & 1.93 & 0.3940 & -0.7724 \\
\hline 2 & 27.41 & 0.8510 & -0.4664 & 2.74 & 0.4281 & -0.7805 \\
\hline 2 & 37.16 & 0.9175 & -0.4284 & 3.89 & 0.6371 & -0.7153 \\
\hline 3 & 5.77 & 1.0578 & -0.1193 & 0.63 & 0.7961 & -0.1998 \\
\hline 3 & 13.34 & 0.8633 & -0.2328 & 1.16 & 0.7182 & -0.2503 \\
\hline 3 & 19.61 & 0.8288 & -0.2624 & 1.93 & 0.6523 & -0.3175 \\
\hline 3 & 27.39 & 0.8274 & -0.2697 & 2.74 & 0.6383 & -0.3491 \\
\hline 3 & 37.17 & 0.7424 & -0.3191 & 3.88 & 0.4451 & -0.5109 \\
\hline 4 & 5.81 & 1.0685 & -0.0812 & 0.63 & 0.8922 & -0.1043 \\
\hline 4 & 13.34 & 0.8768 & -0.1741 & 1.16 & 0.8488 & -0.1275 \\
\hline 4 & 19.62 & 0.8656 & -0.1883 & 1.93 & 0.8106 & -0.1604 \\
\hline 4 & 27.39 & 0.8701 & -0.1906 & 2.74 & 0.7909 & -0.1815 \\
\hline 4 & 37.32 & 0.8174 & -0.2193 & 3.88 & 0.6756 & -0.2449 \\
\hline 5 & 5.81 & 0.9705 & -0.0835 & 0.63 & 0.9357 & -0.0622 \\
\hline 5 & 13.34 & 0.8949 & -0.1329 & 1.16 & 0.9041 & -0.0799 \\
\hline 5 & 19.62 & 0.8795 & -0.1474 & 1.93 & 0.8865 & -0.0962 \\
\hline 5 & 27.40 & 0.8828 & -0.1507 & 2.74 & 0.8716 & -0.1091 \\
\hline 5 & 37.33 & 0.7965 & -0.1917 & 3.88 & 0.7924 & -0.1473 \\
\hline 6 & 5.81 & 1.0085 & -0.0583 & 0.63 & 0.9371 & -0.0522 \\
\hline 6 & 13.34 & 0.9066 & -0.1062 & 1.16 & 0.9320 & -0.0558 \\
\hline 6 & 19.62 & 0.8941 & -0.1175 & 1.93 & 0.9275 & -0.0647 \\
\hline 6 & 27.39 & 0.8927 & -0.1220 & 2.74 & 0.9274 & -0.0681 \\
\hline 6 & 37.33 & 0.8234 & -0.1525 & 3.88 & 0.8534 & -0.1014 \\
\hline 7 & 5.81 & 1.0290 & -0.0362 & 0.63 & 0.9480 & -0.0376 \\
\hline 7 & 13.33 & 0.9221 & -0.0811 & 1.16 & 0.9549 & -0.0377 \\
\hline 7 & 19.63 & 0.9206 & -0.0853 & 1.93 & 0.9564 & -0.0410 \\
\hline 7 & 27.39 & 0.9317 & -0.0823 & 2.74 & 0.9555 & -0.0427 \\
\hline 7 & 37.33 & 0.8853 & -0.1010 & 3.88 & 0.8778 & -0.0770 \\
\hline 8 & 5.81 & 1.0473 & -0.0184 & 0.63 & 0.9812 & -0.0169 \\
\hline 8 & 13.33 & 0.9490 & -0.0557 & 1.16 & 0.9759 & -0.0227 \\
\hline 8 & 19.62 & 0.9470 & -0.0581 & 1.93 & 0.9733 & -0.0261 \\
\hline 8 & 27.39 & 0.9483 & -0.0587 & 2.74 & 0.9752 & -0.0277 \\
\hline 8 & 37.33 & 0.9351 & -0.0626 & 3.88 & 0.9276 & -0.0460 \\
\hline 9 & 5.81 & 1.0274 & -0.0112 & 0.63 & 0.9866 & -0.0099 \\
\hline 9 & 13.33 & 0.9632 & -0.0373 & 1.16 & 0.9946 & -0.0091 \\
\hline 9 & 19.62 & 0.9648 & -0.0374 & 1.93 & 0.9881 & -0.0127 \\
\hline 9 & 27.39 & 0.9673 & -0.0373 & 2.74 & 0.9878 & -0.0145 \\
\hline 9 & 37.33 & 0.9629 & -0.0375 & 3.88 & 0.9689 & -0.0217 \\
\hline 10 & 5.81 & 0.9750 & -0.0222 & 0.63 & 1.0010 & 0.0004 \\
\hline 10 & 13.34 & 0.9754 & -0.0199 & 1.16 & 1.0002 & 0.0000 \\
\hline 10 & 19.62 & 0.9834 & -0.0181 & 1.93 & 1.0021 & 0.0005 \\
\hline 10 & 27.39 & 0.9842 & -0.0182 & 2.74 & 1.0069 & 0.0010 \\
\hline 10 & 37.33 & 0.9907 & -0.0146 & 3.88 & 1.0032 & 0.0010 \\
\hline
\end{tabular}

a The use of the LUT to correct the LAEs for $\mathrm{L}_{t}\left(\right.$ in $\mathrm{W} \mathrm{m}^{-2} \mathrm{um}^{-1} \mathrm{sr}^{-1}$ ) of a certain pixel requires two parameters from the uncorrected image: $(1)$ the TOA radiance of the nearby land pixel $\left(L_{t \_l a n d}\right)$, and the aerosol optical thickness $\left(\tau_{869}\right)$ from the nearby LAE-free ocean pixel. The ratio between LAE-affected and LAE-free pixel (e.g., the LAE) can be estimated as ratio $=\left(\tau_{869}\right)^{\mathrm{a}} \times \mathrm{b}$ (coefficients a and $b$ can be obtained from the LUT for each $\left.L_{t \_l a n d}\right)$, and the $L A E$-corrected $L_{t}\left(L_{t}^{\prime}\right)$ can be derived as $L_{t}^{\prime}=L_{t} /$ ratio. For a given $L_{t \_l a n d}$ that fall between two values of $L_{t \_l a n d}\left(L_{t 1}\right.$ and $\left.L_{t 2}\right)$ in the table, a linear interpolation can be used to determine the ratio using the ratios corresponding to $L_{t 1}$ and $L_{t 2}$.

The LAE correction processes were conducted for images covering the Hawaii Islands with the above steps, where the mean LAEs for each of the two MODIS SWIR bands were calculated using $>5000$ valid land-water transects. Figure 7 shows that after the correction, $\mathrm{LAE}_{\text {corrected }}$ was much closer to 1.0 than $\mathrm{LAE}_{\text {uncorrected }}$ especially for Dist $>2$ pixels. For Dist $=3$ pixels, $L A E_{\text {corrected }}$ were 0.88 and 0.99 for $L_{t, 1240}$ and $L_{t, 2130}$, respectively, while the corresponding $L A E_{\text {uncorrected }}$ were 1.32 and 1.31 , respectively. Although the $1240 \mathrm{~nm}$ band was overcorrected, the overall reduction in LAEs was indeed substantial. 

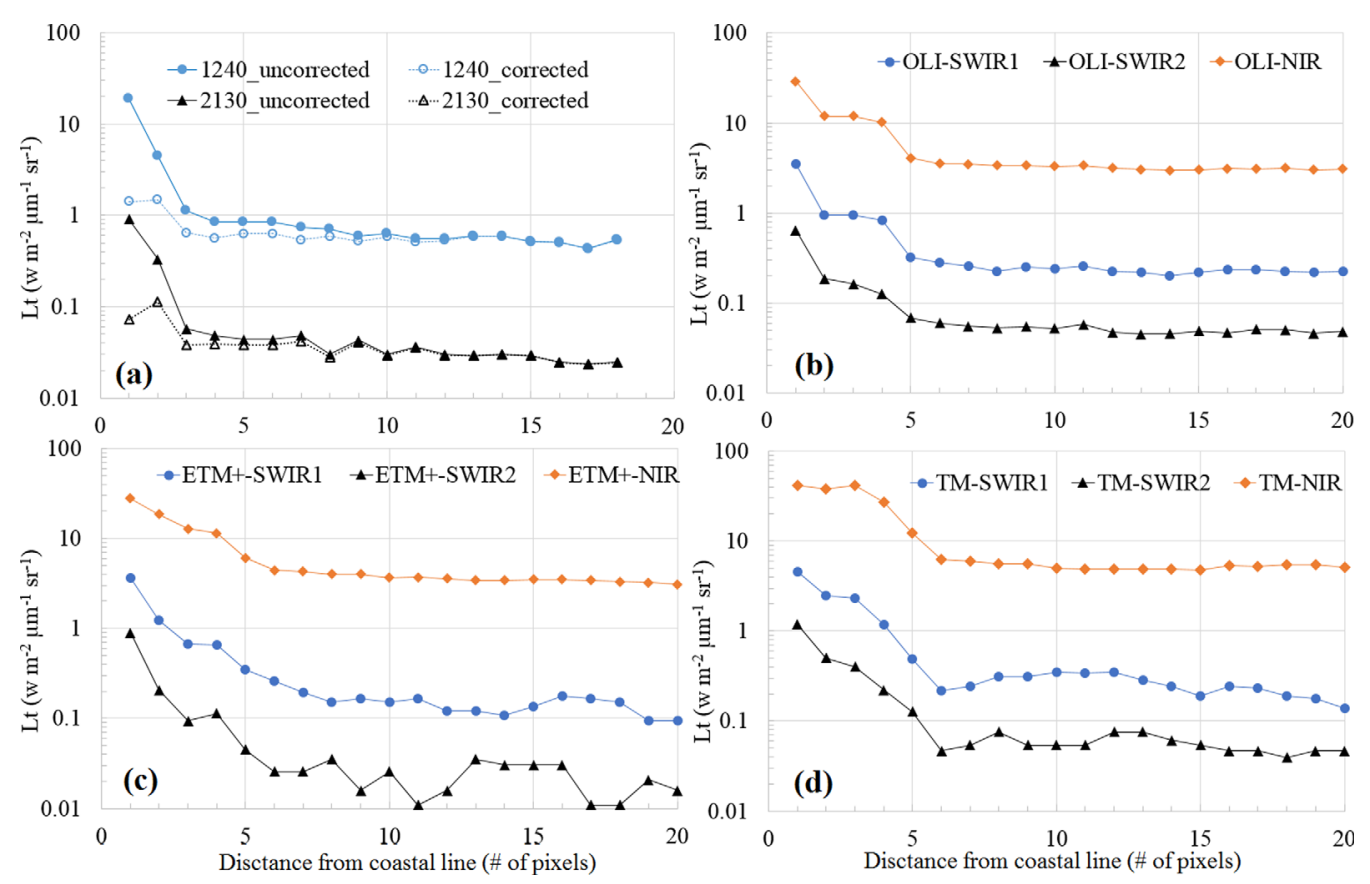

Figure 6. (a) Comparison of the MODISA SWIR $L_{t}$ before and after correction of the LAEs from a typical land-water transect. The image was acquired on 9 June 2003 over the Coastal Madagascar Island. (b) $L_{t}$ transect of two SWIR bands (SWIR1 of 1.57-1.65 $\mu \mathrm{m}$ and SWIR2 of 2.11$2.29 \mu \mathrm{m}$, respectively) and one NIR band $(0.85-0.88 \mu \mathrm{m})$ of Landsat $8 \mathrm{OLI}$ image on 7 May 2015 over the same transect. (c) $L_{t}$ transect of two SWIR bands (SWIR1 of 1.55-1.75 $\mu \mathrm{m}$ and SWIR2 of 2.09-2.35 $\mu \mathrm{m}$, respectively) and one NIR band $(0.77-0.90 \mu \mathrm{m})$ of Landsat 7 ETM+ image on 27 May 2002. (d) $L_{t}$ transect of two SWIR bands (SWIR1 of 1.55-1.75 $\mu \mathrm{m}$ and SWIR2 of 2.08-2.35 $\mu \mathrm{m}$, respectively) and one NIR band $(0.76-0.90 \mu \mathrm{m})$ of Landsat 5 TM image on 21 February 2015. A $3 \times 3$ mean smooth window was applied to TM and ETM + data to reduce their low signal-to-noise ratio-induced speckle noises. Note the difference of spatial resolutions between (a) MODIS (500 m) and (b-d) Landsat instruments (OLI, ETM+, and TM) (30 m).

\subsubsection{Performances of the LAEs Correction on Chl-a Retrieval}

In situ Chl-a data collected from Chesapeake Bay were used to assess the performance of the LAE correction scheme for Chl-a retrievals over coastal waters. To do this, MODISA data were processed using SeaDAS twice. The first was the default processing using the 1240 and $2130 \mathrm{~nm}$ bands for atmospheric correction

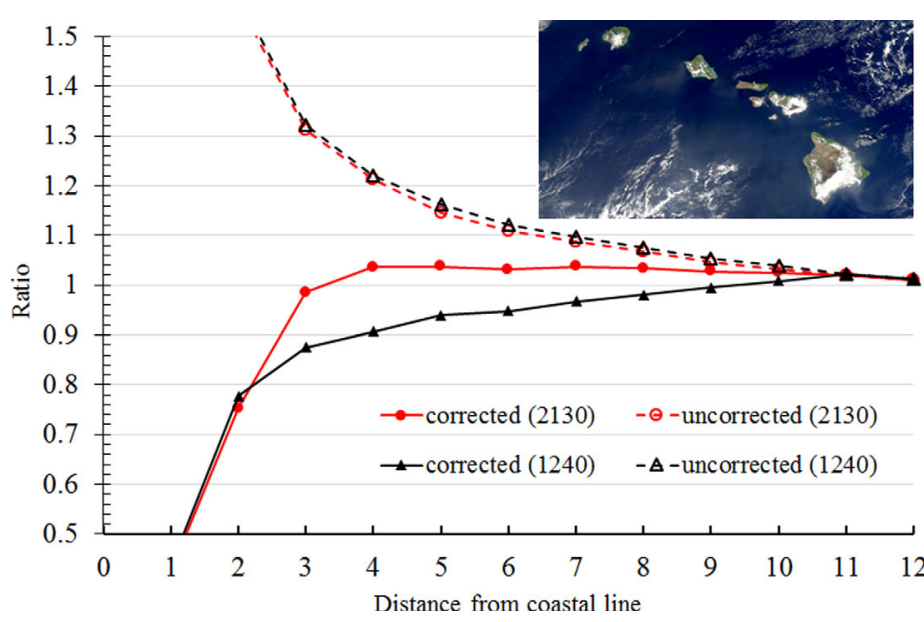

Figure 7. Comparison of LAEs between corrected and uncorrected data for MODIS Aqua $L_{t}$ data in two SWIR bands over the Hawaii Islands coastal waters. A ratio $=1.0$ means no LAEs from the current pixel, and a ratio of $>1.0$ indicates nonzero LAEs. The correction used the LUT in Table 1 generated from the Madagascar Island between 2003 and 2012, and the results in this figure were generated using statistics of $>10,000$ transects that are perpendicular to the coastlines of the Hawaii Islands. The distance is expressed as \# of 500-m pixels.
[Wang and Shi, 2007] to produce $R_{r s}$ in the visible bands, from which $\mathrm{Chl}-\mathrm{a}$ was estimated using the default OC4 algorithm [O'Reilly et al., 1998]. The second was the same processing except that the 1240 and $2130 \mathrm{~nm}$ bands were corrected for their LAEs using the scheme above. The match-ups between the satellite Chl-a retrievals and in situ measurements were selected following the approach recommended by Bailey and Werdell [2006].

Statistical measures between satellite and in situ Chl-a were used to evaluate satellite data quality, including RMSE (root mean square error), MRE (mean relative error), $R^{2}, R^{2}$ of log- 

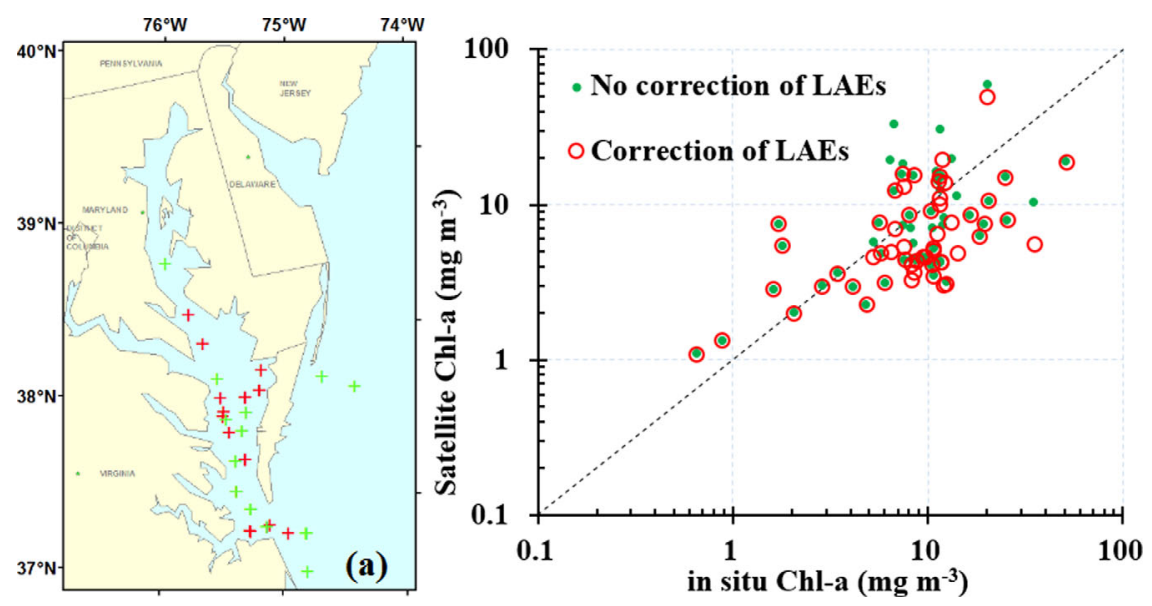

Figure 8. (a) Locations of the satellite-to-in situ Chl-a match ups in the Chesapeake Bay. Red (green) symbols represent locations where the retrieved Chl-a values changed (did not change) after applying the LAE corrections. Total number of locations is 56. (b) Comparisons between MODIS-retrieved and in situ Chl-a over the 56 locations before and after applying the LAEs correction in the SWIR atmospheric correction. The statistical measures can be found in Table 2 .

transformed Chl-a $\left(\mathrm{R}^{2}(\mathrm{log})\right)$ and mean ratio. As shown in Figure 8 a of the 56 match-ups, LAE corrections were applied to 35 points (red), and the remaining 21 points (green) were either free of LAEs (e.g., Dist $>10$ pixels) or with no valid reference $\tau_{869}$ pixels (see steps above). Comparing with those from the uncorrected SWIR bands, Chl-a retrieved from the LAE corrected SWIR bands (SWIR corrected $_{\text {) }}$ showed significant improvements in accuracy. Lower RMSE, lower MRE, higher $\mathrm{R}^{2}$, and higher $\mathrm{R}^{2}(\mathrm{log})$ were found from the latter, regardless of whether the measures were calculated using all the 56 points or the 35 LAEs corrected points (Table 2). Likewise, the mean ratios between MODISAretrieved $\mathrm{Chl}-\mathrm{a}$ and in situ $\mathrm{Chl}-\mathrm{a}$ were also closer to 1.0 after the LAE corrections. On the other hand, the use of the NIR bands led to better Chl-a retrievals than the use of SWIR bands without LAEs correction (Table 2), a result consistent with the study of Werdell et al. [2010]. However, after the LAEs correction of the SWIR bands, the same SWIR atmospheric correction yielded improved Chl-a retrievals with comparable to the NASA default Chl-a, indicating the feasibility of the LUT-based LAEs correction scheme.

The LAE correction results can also be visualized through inspection of the Chl-a maps. Figure 9 shows the $\mathrm{Chl}$-a retrievals using both uncorrected and corrected SWIR bands in the atmospheric correction. High Chl-a estimates can be found along the coastline of the western side of the bay when the LAEs were not corrected, while some of these potential artifacts were substantially reduced after the LAEs correction was applied based on the LUT in Table 1. On the other hand, along the coastline of the eastern side of the bay there appear to be some overcorrections within 2 pixels of shoreline (red circled in Figure 9b), leading to low values that do not appear realistic.

Table 2. Statistical Measures for the MODIS Aqua Satellite-to-In Situ Chl-a Validation Results Before and After the LAEs Correction in the SWIR Atmospheric Correction over the Chesapeake Bay (Figure 8) ${ }^{\text {a }}$

\begin{tabular}{llcccccc} 
& & RMSE (\%) & MRE (\%) & $R^{2}$ & $R^{2}(\log )$ & Mean Ratio & n_points \\
\hline All locations & No LAEs correction & 101.3 & 68.3 & 0.10 & 0.35 & 1.18 & 56 \\
& With LAEs correction & 77.1 & 56.7 & 0.16 & 0.36 & 0.95 & 56 \\
All locations & NASA default Chl-a & 81.8 & 53.8 & 0.27 & 0.52 & 1.26 & 56 \\
Locations with Chl-a changes & No LAEs correction & 122.2 & 82.5 & 0.03 & 0.09 & 1.42 & 35 \\
& With LAEs correction & 89.6 & 64.0 & 0.05 & 0.08 & 1.05 & 35 \\
\hline
\end{tabular}

${ }^{\text {a }}$ The results for the NASA default Chl-a estimates from the NIR atmospheric correction are also listed in the third row as a reference. The first two rows show the statistics before and after the LAEs correction over all 56 locations. The last two rows show the statistics before and after the LAEs correction over only those 35 stations where MODIS-retrieved Chl-a values changed (i.e., the LAEs had no effect on the other 21 stations). 


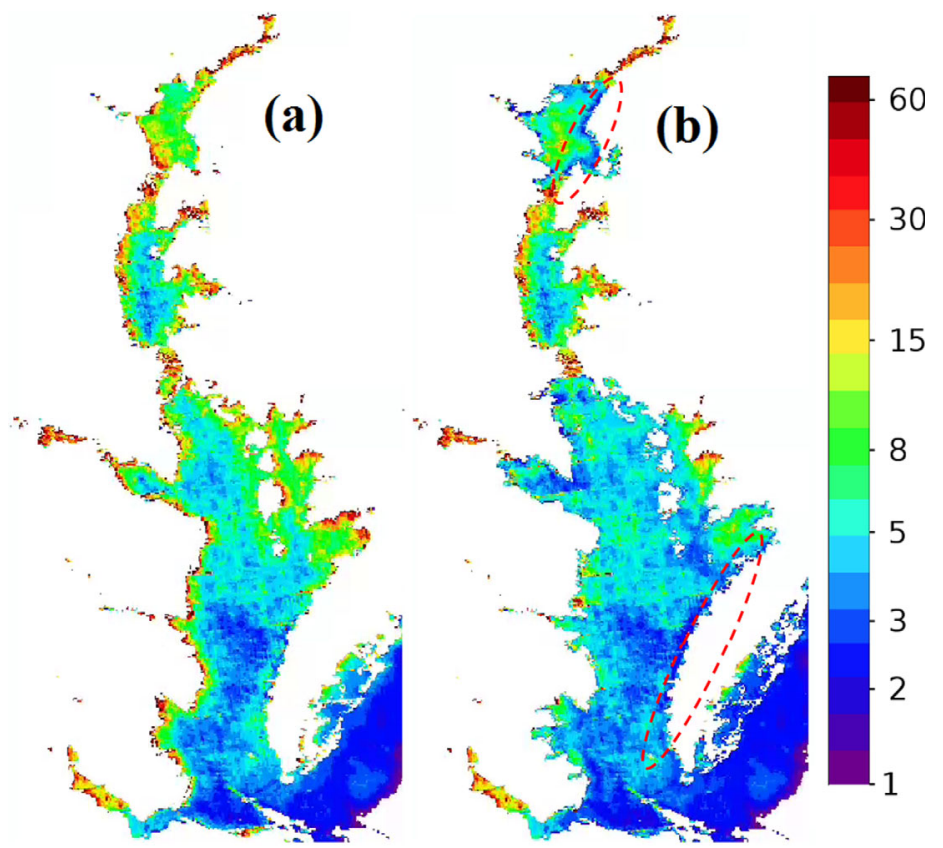

Figure 9. MODIS retrieved Chl-a concentrations (in $\mathrm{mg} \mathrm{m}^{-3}$ ) of Chesapeake Bay on 9 June 2004 (a) before and (b) after LAE correction in the SWIR atmospheric correction. In general, $\mathrm{Chl}$-a values near coastlines after the LAEs correction are lower than without LAEs correction.

\section{Discussion}

5.1. Uncertainties and Limitations of the LAEs Estimates

Two assumptions were used in the estimation of LAEs in the two SWIR bands: (1) the waterleaving signal of the SWIR bands is $\sim 0$ in nearshore waters; (2) aerosols have no spatial gradient for Dist $<15$ pixels (or $<7.5 \mathrm{~km}$ at nadir). For the case of Madagascar Island, these two assumptions should be valid because of extremely high water absorption in the SWIR wavelengths [Hale and Querry, 1973] and lack of sediment source (assumption 1), and because of the easterly winds from the ocean to the land, as revealed from NCEP data. However, the LAEs were estimated for the specific land morphology of the Madagascar Island with a long straight shoreline where ocean waters are on the east side of the island. For waters to the west side of land, the results may be different, especially when considering the sensor memory effect [Feng and $\mathrm{Hu}, 2016]$. Likewise, for waters surrounded by land of irregular shapes, signals from multiple directions may accumulate, leading to stronger LAEs than shown here. These effects may explain why the LAE correction may have failed for some nearshore pixels along the east side of Chesapeake Bay (red circles in Figure 9b). However, in practice, it is impossible to derive statistical meaningful LAEs for all possible morphological shoreline features, making LAE correction still an extremely challenging task. Nevertheless, the findings from this work at least provide first estimates of LAEs from one specific shoreline morphology, from which a method to correct the LAEs has been demonstrated to provide a possible pathway for future work.

The low SNRs of the SWIR bands could cause digitization noise errors [Hu et al., 2001, 2012], resulting in errors in the retrieved $R_{r s}$ as well as artifacts in the LAE calculations if one single water-land transect were to be used (e.g., $L_{t}$ transect in Figure 6a). Such noise-induced errors could be reduced substantially through data binning, where the LAEs were calculated using $>50$ valid transects for each bin of different aerosols and $\mathrm{L}_{\mathrm{t}}$ land values. Indeed, the correction scheme, established using the LUT of the mean LAEs, demonstrated its feasibility in LAE reductions in the test regions of the Hawaii Islands and the Chesapeake Bay. However, it is also acknowledged that the proposed correction method requires further work before it can be implemented in an operational software (e.g., SeaDAS) in order to account for the remaining issues of complex coastal morphology, sensor memory effects, different land surface features, and various aerosol types. In any case, LAEs represents only one source of $\mathrm{R}_{\mathrm{rs}}$ uncertainty, therefore efforts in reducing uncertainties from other sources (e.g., improve SNRs in the SWIR bands, improved atmospheric correction scheme) are still required.

\subsection{LAEs in the NIR Bands}

The estimation of LAEs was focused on the SWIR bands water-leaving radiance even in nearshore waters of this remote island should be negligible (assumption \#1 above), yet the method should be applicable to other bands as long as assumption \#1 is also valid. Because of the remote location of the Madagascar Island with minimal sediment load, perhaps it is reasonable to extend the assumption \#1 to the 748 and $869 \mathrm{~nm}$ NIR bands as well. Then, using the same method, LAEs in the NIR bands as a function of Dist were estimated and shown in Figure 10a. Because assumption \#1 is likely true for this particular environment, any ratio $>1.0$ in Figure 10a may be regarded as from LAEs. It is clear that LAEs in both NIR bands are significant for 

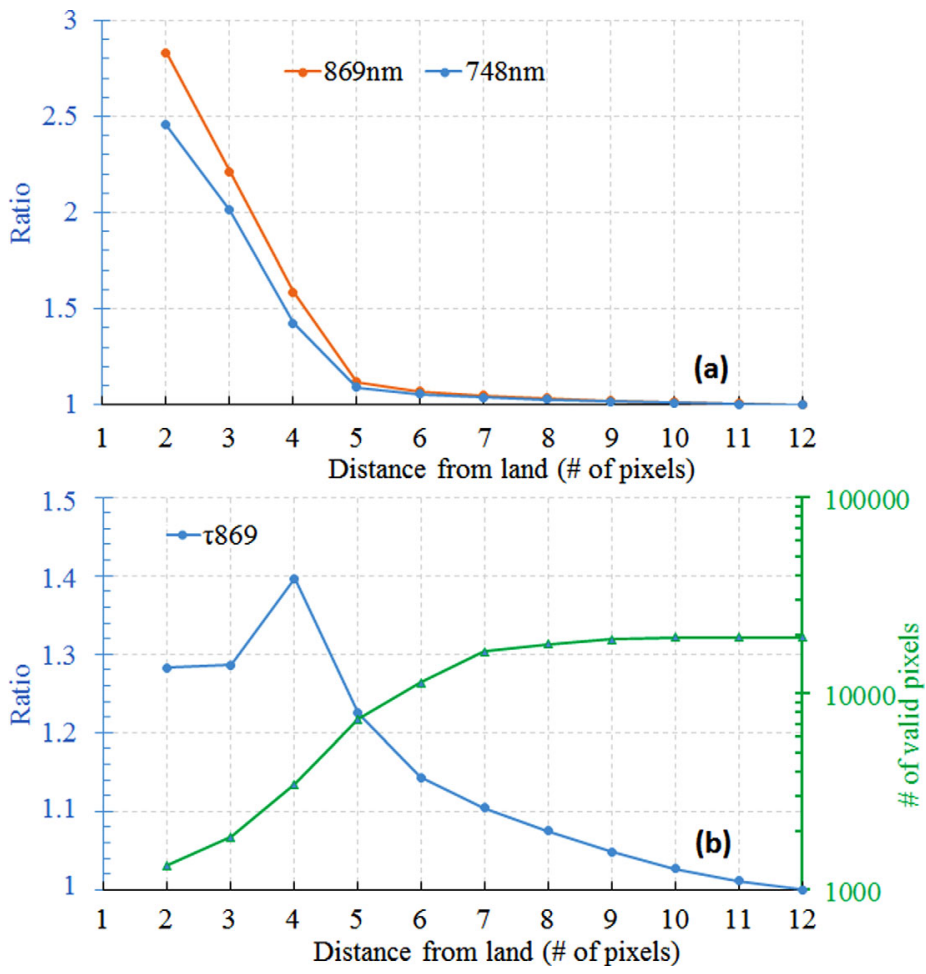

Figure 10. (a) LAEs of MODIS $L_{t}$ in the 748 and $869 \mathrm{~nm}$ bands, expressed as the ratio of $L_{t}$ between the current pixel and pixels far away from land of the Madagascar Island. $A$ ratio $=1.0$ means no LAEs from the current pixel, and a ratio of $>1.0$ indicates nonzero LAEs. (b) LAEs in the retrieved $\tau_{869}$, expressed as the ratio between $\tau_{869}$ of the current pixel and pixels far away from land. Also plotted is the number of valid points as a function of Dist. Each pixel is about $500 \mathrm{~m}$ in ground resolution.
Dist $<5$ pixels, and for Dist $=2-$ 3 pixels the ratios are $>2.0$, meaning that the LAEs are greater than the atmospheric path radiance in the absence of LAEs. This observation agrees very well with the simulated results in Santer and Schmechtig [2000], but not well with the simulated results in Bulgarelli et al. [2014], which showed LAEs at $865 \mathrm{~nm}$ of around $\sim 11 \%$, possibly due to the relative large sea surface albedo (0.04) used in the simulations.

\subsection{Impacts of LAEs on Data} Product Accuracy

The significant LAEs in the SWIR bands and NIR bands (ratio $\gg$ 1.0 in Figures 3 and 10a, respectively) can lead to overestimation of the aerosol contribution [Shi and Wang, 2012] and consequently underestimation of the water-leaving radiance. The latter for turbid coastal waters has often been attributed to nonzero water-leaving radiance in the NIR in earlier studies [e.g., $\mathrm{Hu}$

et al., 2000; Ruddick et al., 2000; Siegel et al., 2000], yet the findings suggest that errors in the retrieved data products can also be attributed to LAEs for at least the first few pixels from land. Figure 10b shows $\tau_{869}$ ratio (against pixels away from land) as a function of Dist, where $\tau_{869}$ is shown to be overestimated by $\sim 40 \%$ for Dist $=4$ pixels. Such an overestimation will lead to underestimation of water-leaving radiance in the visible bands.

\subsection{LAEs for Different Instruments}

Many high-resolution instruments are equipped with SWIR bands, such as the Landsat sensors (TM, ETM+, and OLI) and the Sentinel-2 Multispectral instrument (MSI). The question is whether these sensors experience similar LAEs and the developed LUT can also be applied to these sensors. Figure $6 \mathrm{~b}$ plots the $\mathrm{L}_{t}$ transects for two SWIR bands (SWIR1 of 1.57-1.65 $\mu \mathrm{m}$ and SWIR2 of 2.11-2.29 $\mu \mathrm{m}$ ) from a Landsat 8 OLI image, which was collected on 7 May 2015 over the same coastal oceans of the Madagascar Island. With a much higher spatial resolution $(30 \mathrm{~m}$ ) than MODISA (500 m), the number of LAE-affected pixels near shorelines for Landsat $8 \mathrm{OLI}$ appears to be comparable to MODISA ( $\sim 10$ pixels). Furthermore, the numbers of LAEaffected pixels for the SWIR bands of Landsat TM and ETM+ (Figures 10c and 10d), as well as for the NIR bands of the three different Landsat instruments are also very similar. Because of the different pixel resolutions, however, the LAE-affected distance, in terms of kilometers, is significantly different between the Landsat and MODISA sensors. This finding is actually encouraging for applications of Landsat-like sensors to capture small-scale features in turbid coastal or inland waters [Vanhellemont and Ruddick, 2014], for otherwise if it were the physical distance rather than number of pixels that is important for LAEs, $4500 \mathrm{~m} \mathrm{MOD-}$ ISA pixels would be equivalent to $6630 \mathrm{~m}$ Landsat pixels, resulting in many pixels subject to large uncertainties due to LAEs in the SWIR and NIR bands.

\subsection{Implications for Data Recovery}

The LAEs in the SWIR bands lead to significant overestimation of aerosols and underestimation of $R_{r s}$ in some of the land adjacent oceans, or sometimes can cause atmospheric correction failure because the 


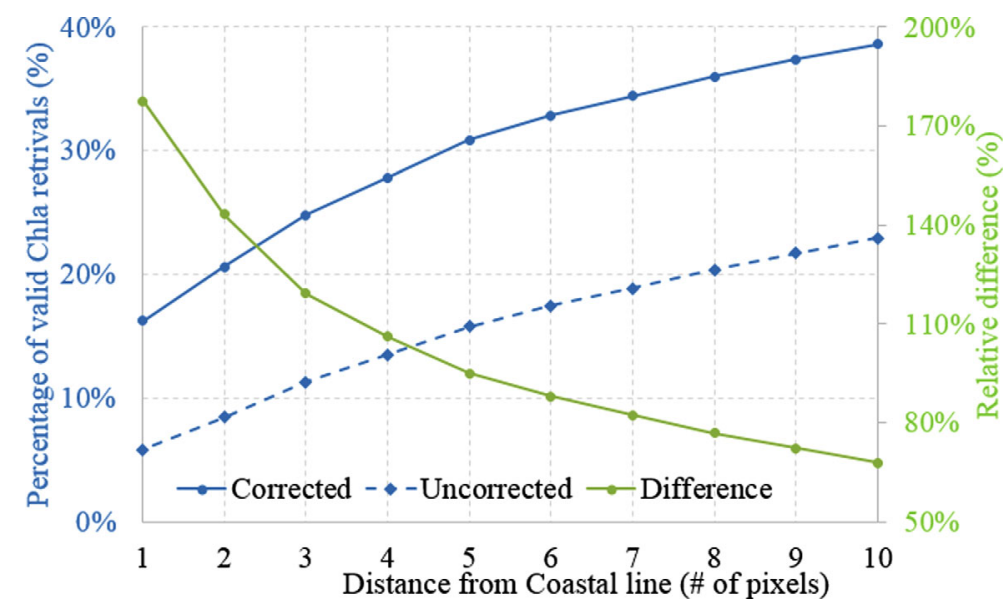

Figure 11. Percentages of valid Chl-a retrievals (e.g., Chl-a $>0$ and $<64 \mathrm{mg} \mathrm{m}^{-3}$ ) from 171 MODIS Aqua images over the Chesapeake Bay as a function of distance to coastline, with the results derived using the SWIR AC with and without LAEs corrected for the SWIR bands. Also plotted is the relative difference (in percentage) between the two methods. atmospheric correction process cannot find two aerosol models to bracket the associated aerosol scattering epsilon value $(\epsilon)$ [Gordon and Wang, 1994; Wang and Shi, 2007]. After the LAEs are reduced using the derived LUT here, some of the previous invalid ocean color retrievals due to either negative $\mathrm{R}_{\mathrm{rs}}$ or atmospheric correction failure may be recovered.

Figure 11 shows the statistics of the percentages of valid Chl-a retrievals (POVCs) from MODISA images as function of Dist,

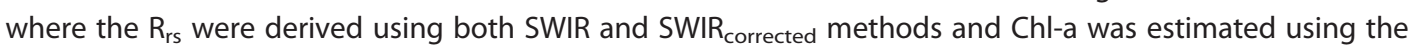
blue/green band ratio algorithm. Here the term "valid" refers to Chl-a values between 0.0 and $64.0 \mathrm{mg} \mathrm{m}^{-3}$. The results were generated using 171 MODISA over Chesapeake Bay, and the POVCs were calculated as the number of valid Chl-a pixels divided by the total number of MODISA pixels. Clearly, the POVCs obtained with the SWIR corrected were significantly higher $(>60 \%)$ than those from the original SWIR data for Dist $\leq 10$ pixels. Whether these recovered pixels are accurate or at least statistically not worse than pixels immune to LAEs, still requires further test when groundtruth data are more abundant than shown here.

\section{Conclusions}

Satellite TOA radiances near land suffer from LAEs, especially for the SWIR bands that are often used for atmospheric correction over extremely turbid waters. Here the LAEs of two MODISA SWIR bands at 1240 and $2130 \mathrm{~nm}$ have been statistically characterized with 11-year observations from the regular-shaped east coast of the Madagascar Island. The LAEs on TOA radiance, expressed as the ratio between the LAE-affected and the LAE-free pixels, decrease sharply with the increasing distance to shorelines, and such a decreasing pattern appears to be universal for all sensors evaluated. One significant finding is that the decreasing pattern is similar in pixel space rather than in physical distance among different sensors. The dependency of LAEs on adjacent land signal and aerosol thickness was revealed, based on which an LAE LUT was generated to correct the LAEs of the MODISA SWIR data collected over coastal waters other than those around the Madagascar Island. Some preliminary progress has been made in reducing the number of invalid pixels after the correction, yet more work is still required for improved correction.

\section{Notations}

MODISA Moderate Resolution Imaging Spectroradiometer on Aqua

TSS total suspended sediments $\left(\mathrm{mg} \mathrm{L}^{-1}\right)$

Chl-a chlorophyll a concentration $\left(\mathrm{mg} \mathrm{m}^{-3}\right)$

CDOM colored dissolved organic matter

$\mathrm{L}_{\mathrm{t}} \quad$ top-of-atmosphere (TOA) radiance $\left(\mathrm{W} \mathrm{m}^{-2} \mu \mathrm{m}^{-1} \mathrm{sr}^{-1}\right.$ )

$\mathrm{R}_{\mathrm{rs}} \quad$ remote sensing reflectance $\left(\mathrm{sr}^{-1}\right)$

LAEs land adjacency effects

AC atmospheric correction

SWIR short-wave infrared

NIR near-infrared

POVC percentages of valid Chl-a retrievals 


\author{
PSF point spread function \\ RT radiative transfer \\ Dist distance from shoreline (number of pixels) \\ LUT look-up-table \\ NDVI normalized difference vegetation index \\ NDWI normalized difference water index
}

\section{References}

Bailey, S. W., and P. J. Werdell (2006), A multi-sensor approach for the on-orbit validation of ocean color satellite data products, Remote Sens. Environ., 102(1), 12-23.

Barnes, R. A., A. W. Holmes, W. L. Barnes, W. E. Esaias, C. R. Mcclain, T. Svitek, S. B. Hooker, E. R. Firestone, and J. G. Acker (1994), SeaWiFS Technical Report Series, vol. 23, SeaWiFS Prelaunch Radiometric Calibration and Spectral Characterization, NASA Technical Memorandum 104566, Md.

Bulgarelli, B., V. Kiselev, and G. Zibordi (2014), Simulation and analysis of adjacency effects in coastal waters: A case study, Appl. Opt., 53(8), 1523-1545.

Darecki, M., and D. Stramski (2004), An evaluation of MODIS and SeaWiFS bio-optical algorithms in the Baltic Sea, Remote Sens. Environ., 89(3), 326-350.

Feng, L., and C. Hu (2016), Cloud adjacency effects on top-of-atmosphere radiance and ocean color data products: A statistical assessment, Remote Sens. Environ., 174, 301-313.

Feng, L., C. Hu, X. Chen, and Q. Song (2014), Influence of the Three Gorges Dam on total suspended matters in the Yangtze Estuary and its adjacent coastal waters: Observations from MODIS, Remote Sens. Environ., 140, 779-788.

Gordon, H. R. (1997), Atmospheric correction of ocean color imagery in the Earth Observing System era, J. Geophys. Res., 102, 17,081$17,106$.

Gordon, H. R., and M. Wang (1994), Retrieval of water-leaving radiance and aerosol optical thickness over the oceans with SeaWiFS: A preliminary algorithm, Appl. Opt., 33(3), 443-452.

Hale, G. M., and M. R. Querry (1973), Optical constants of water in the 200-nm to 200- $\mu$ m wavelength region, Appl. Opt., 12(3), 555-563.

$\mathrm{Hu}$, C., K. L. Carder, and F. E. Muller-Karger (2000), Atmospheric correction of SeaWiFS imagery over turbid coastal waters: A practical method, Remote Sens. Environ., 74(2), 195-206.

Hu, C., K. L. Carder, and F. E. Muller-Karger (2001), How precise are SeaWiFS ocean color estimates? Implications of digitization-noise errors, Remote Sens. Environ., 76(2), 239-249.

Hu, C., Z. Chen, T. D. Clayton, P. Swarzenski, J. C. Brock, and F. E. Muller-Karger (2004), Assessment of estuarine water-quality indicators using MODIS medium-resolution bands: Initial results from Tampa Bay, FL, Remote Sens. Environ., 93(3), 423-441.

Hu, C., L. Feng, Z. Lee, C. O. Davis, A. Mannino, C. R. McClain, and B. A. Franz (2012), Dynamic range and sensitivity requirements of satellite ocean color sensors: Learning from the past, Appl. Opt., 51(25), 6045-6062.

Hu, C., L. Feng, and Z. Lee (2013), Uncertainties of SeaWiFS and MODIS remote sensing reflectance: Implications from clear water measurements, Remote Sens. Environ., 133, 168-182.

Jiang, L., and M. Wang (2013), Identification of pixels with stray light and cloud shadow contaminations in the satellite ocean color data processing, Appl. Opt., 52(27), 6757-6770.

Kiselev, V., B. Bulgarelli, and T. Heege (2015), Sensor independent adjacency correction algorithm for coastal and inland water systems, Remote Sens. Environ., 157, 85-95.

Levy, R. C., L. A. Remer, S. Mattoo, E. F. Vermote, and Y. J. Kaufman (2007), Second-generation operational algorithm: Retrieval of aerosol properties over land from inversion of Moderate Resolution Imaging Spectroradiometer spectral reflectance, J. Geophys. Res., 112, D13211, doi:10.1029/2006JD007811.

Meister, G., and C. R. McClain (2010), Point-spread function of the ocean color bands of the Moderate Resolution Imaging Spectroradiometer on Aqua, Appl. Opt., 49(32), 6276-6285.

Miller, R. L., and B. A. McKee (2004), Using MODIS Terra $250 \mathrm{~m}$ imagery to map concentrations of total suspended matter in coastal waters, Remote Sens. Environ., 93(1-2), 259-266, doi:10.1016/j.rse.2004.07.012.

Minomura, M., H. Kuze, and N. Takeuchi (2001), Adjacency effect in the atmospheric correction of satellite remote sensing data: Evaluation of the influence of aerosol extinction profiles, Opt. Rev., 8(2), 133-141.

Moore, T. S., J. W. Campbell, and H. Feng (2015), Characterizing the uncertainties in spectral remote sensing reflectance for SeaWiFS and MODIS-Aqua based on global in situ matchup data sets, Remote Sens. Environ., 159, 14-27.

O'Reilly, J. E., S. Maritorena, B. G. Mitchell, D. A. Siegel, K. L. Carder, S. A. Garver, M. Kahru, and C. McClain (1998), Ocean color chlorophyll algorithms for SeaWiFS, J. Geophys. Res., 103, 24,937-24,953.

Qi, L., Z. Lee, C. Hu, and M. Wang (2017), Requirement of minimal signal-to-noise ratios of ocean color sensors and uncertainties of ocean color products, J. Geophys. Res. Oceans, 122, 2595-2611, doi:10.1002/2016JC012558.

Reinersman, P. N., and K. L. Carder (1995), Monte Carlo simulation of the atmospheric point-spread function with an application to correction for the adjacency effect, Appl. Opt., 34(21), 4453-4471.

Ruddick, K. G., F. Ovidio, and M. Rijkeboer (2000), Atmospheric correction of SeaWiFS imagery for turbid coastal and inland waters, Appl. Opt., 39(6), 897-912.

Santer, R., and C. Schmechtig (2000), Adjacency effects on water surfaces: Primary scattering approximation and sensitivity study, Appl. Opt., 39(3), 361-375.

Shi, W., and M. Wang (2012), Satellite views of the Bohai Sea, Yellow Sea, and East China Sea, Prog. Oceanogr., 104, 30-45.

Siegel, D. A., M. Wang, S. Maritorena, and W. Robinson (2000), Atmospheric correction of satellite ocean color imagery: The black pixel assumption, Appl. Opt., 39(21), 3582-3591.

Vanhellemont, Q., and K. Ruddick (2014), Turbid wakes associated with offshore wind turbines observed with Landsat 8, Remote Sens. Environ., 145, 105-115.

Wang, M., and W. Shi (2007), The NIR-SWIR combined atmospheric correction approach for MODIS ocean color data processing, Opt. Express, 15(24), 15,722-15,733. 
Wang, M., S. Son, and W. Shi (2009), Evaluation of MODIS SWIR and NIR-SWIR atmospheric correction algorithms using SeaBASS data, Remote Sens. Environ., 113(3), 635-644.

Wang, M., H. R. Gordon, and S. Maritorena (2012), Ocean science requirements supplement: Parameter ranges, regrieval sensitivities to noise, and signal-to-noise requirements for hyperspectral $(5 \mathrm{~nm}$ ) bands (sections A.2 and A.3), in Appendix A of the PACE Mission Science Definition Team Report by Carlos et al., NASA Goddard Space Flight Cent., Greenbelt, Md.

Werdell, P. J., and S. W. Bailey (2005), An improved in-situ bio-optical data set for ocean color algorithm development and satellite data product validation, Remote Sens. Environ., 98(1), 122-140.

Werdell, P. J., S. W. Bailey, B. A. Franz, L. W. Harding, G. C. Feldman, and C. R. McClain (2009), Regional and seasonal variability of chlorophyll-a in Chesapeake Bay as observed by SeaWiFS and MODIS-Aqua, Remote Sens. Environ., 113(6), 1319-1330.

Werdell, P. J., B. A. Franz, and S. W. Bailey (2010), Evaluation of shortwave infrared atmospheric correction for ocean color remote sensing of Chesapeake Bay, Remote Sens. Environ., 114(10), 2238-2247.

Wessel, P., and W. H. Smith (1996), A global, self-consistent, hierarchical, high-resolution shoreline, J. Geophys. Res., 101, $8741-8743$. 